University of Redlands

\title{
Impact Analysis of International Aid in Cambodia through Web GIS
}

A Major Individual Project submitted in partial satisfaction of the requirements for the degree of Master of Science in Geographic Information Systems

by

Kaytlin Jeanette Colburn

Fang Ren, Ph.D., Committee Chair

Mark Kumler, Ph.D.

December 2013 
Impact Analysis of International Aid in Cambodia through Web GIS

Copyright (C) 2013

by

Kaytlin Jeanette Colburn 
The report of Kaytlin Jeanette Colburn is approved.

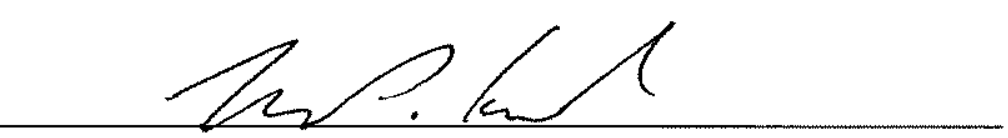

Mark Kumler, Ph.D.

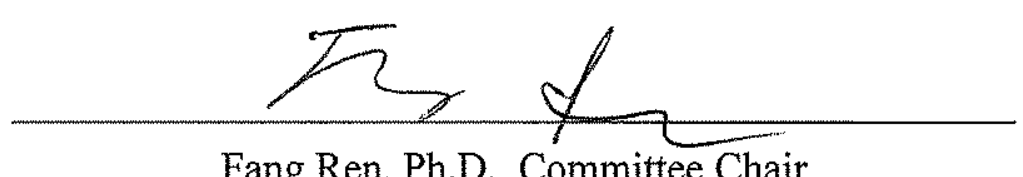

Fang Ren, Ph.D., Committee Chair

December 2013 



\section{Acknowledgements}

First and foremost, this project and the entire experience that went with it would not have been possible without the support of my fantastic family. Your love and support means the world to me.

Thank you Fang for all of your support as my advisor, even when you were on the other side of the globe. Your advising made this project its best possible version of itself. Thank you to Mark for being my "adopted advisor" and to Doug and Ruijin for challenging me in class. Each of the faculty here has given me a new perspective and has truly changed my life. Thanks to all the folks at Esri who took time out of their day to offer guidance and assistance. Most of all, big thanks goes out to Debbie for the candy, the tissue boxes, pep talks, and encouragement to keep going. I am so grateful to have had this fantastic experience thanks to all the amazing people at Redlands.

Thank you to all my fellow students for providing a real sense of community. Enormous thanks goes out to the members of cohort 22, who were mentors and role models in this gargantuan task of completing a Master's in 1 year, and cohort 24, who reminded me of the importance of leaving my apartment every now and then to enjoy the beautiful California sunshine. And finally, thank you to my fellow members of cohort 23. We did it! 
This is dedicated to my Uncle Don. I reached my unreachable star! 


\begin{abstract}
Impact Analysis of International Humanitarian Aid in Cambodia through Web GIS
\end{abstract}

by

Kaytlin Jeanette Colburn

Charities can benefit greatly from web GIS because of the unique ability to measure impact they have in communities they serve, with their stakeholders and potential donors through web maps. The Trailblazer Foundation has been working in Siem Reap, Cambodia, one of the poorest provinces in Cambodia, for nearly a decade. They primarily install bio-sand water filters, in addition to other sustainable community development projects in areas of greatest need. The web mapping application built for this project allows the Trailblazer Foundation to analyze its impact in Siem Reap and share results, all in a web-based environment. Spatial analysis was conducted to compare living conditions of project beneficiaries over time, and compare to results throughout the province as well as identify areas within Siem Reap that require more attention as a result of significantly poorer living conditions measured by survey results. The interactive application allows stakeholders with little to no GIS experience to explore the data and inform themselves of the difference Trailblazer Foundation has made in the lives of rural Cambodians. This project is an example of how GIS can improve lives by identifying areas of greatest need and connecting those communities with the resources that enable healthier lives. 



\section{Table of Contents}

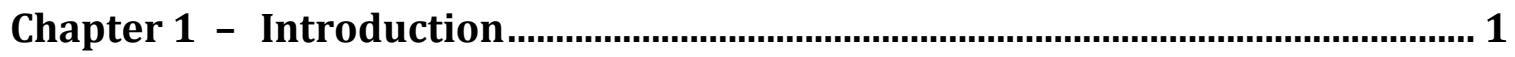

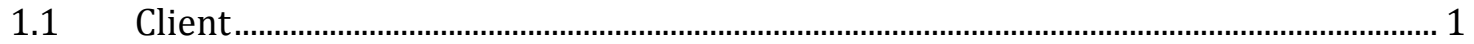

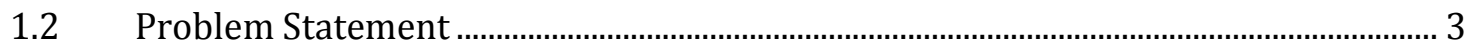

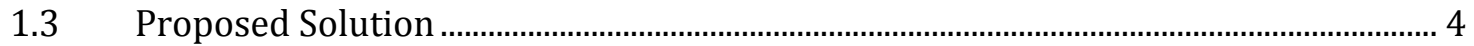

1.3.1 Goals and Objectives ..................................................................................................... 4

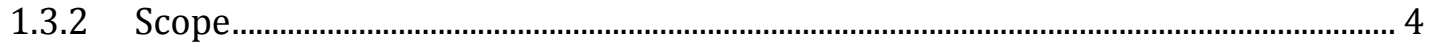



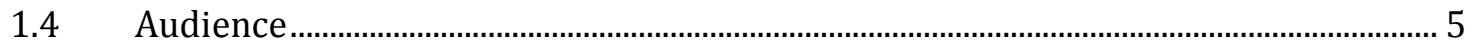

1.5 Overview of the Rest of this Report .................................................................................. 5

Chapter 2 - Background and Literature Review ……............................................ 7

$2.1 \quad$ Why Web GIS? ............................................................................................................ 7

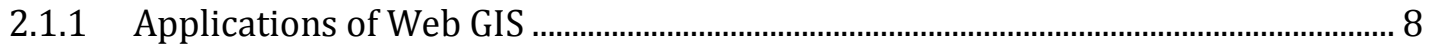

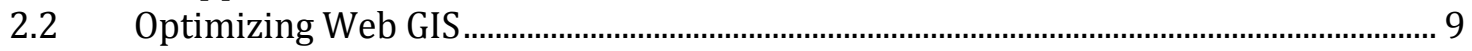

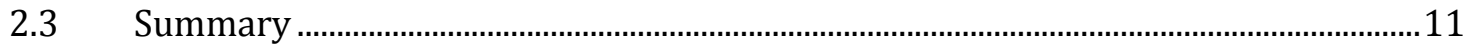

Chapter 3 - Systems Analysis and Design ............................................................13

3.1 Problem Statement .........................................................................................................13

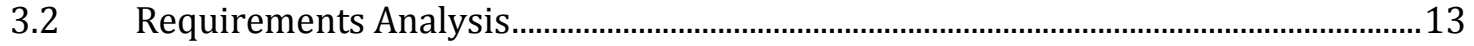

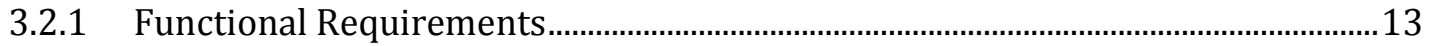

3.2.2 Nonfunctional Requirements .......................................................................................14

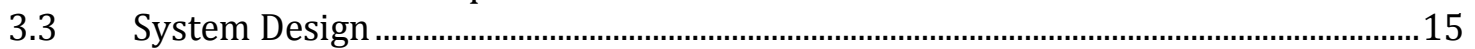

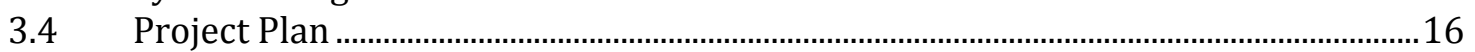

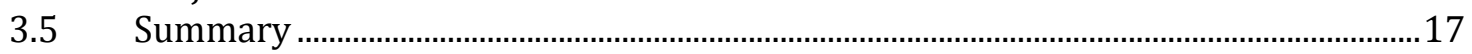

Chapter 4 - Database Design ............................................................................19

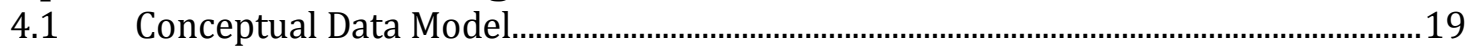

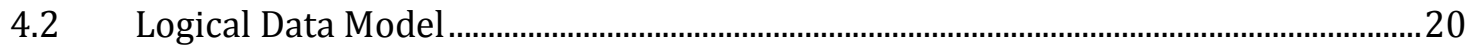

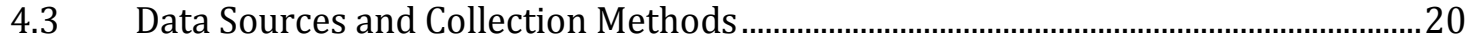

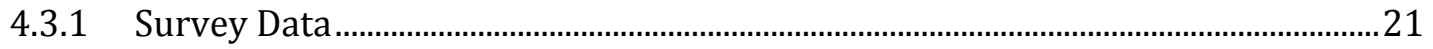

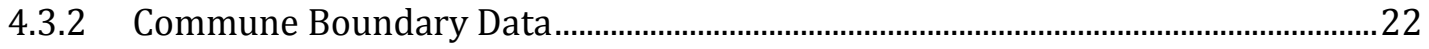

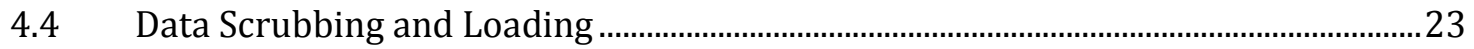

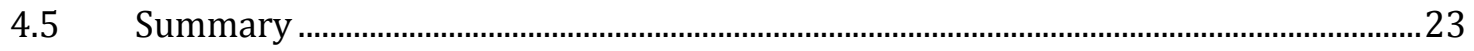

Chapter 5 - Implementation ...............................................................................25

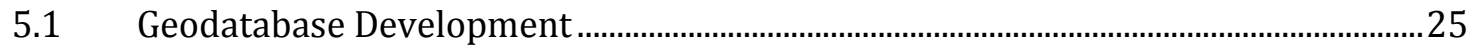

5.2 Web Application Development …………………………………………………………..2

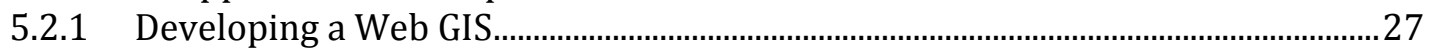

5.2.2 Publishing to the Web................................................................................................28

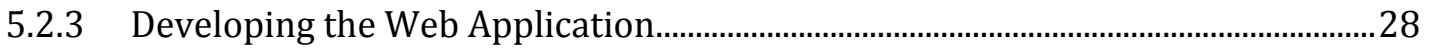

5.3 Functionality of the Web Applications...............................................................................29

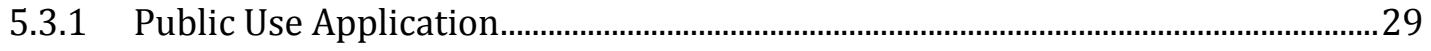

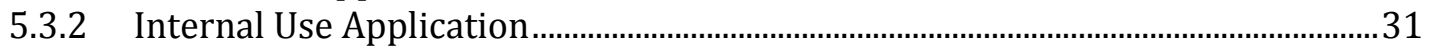

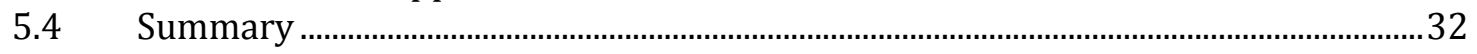

Chapter 6 - Results and Analysis ......................................................................33

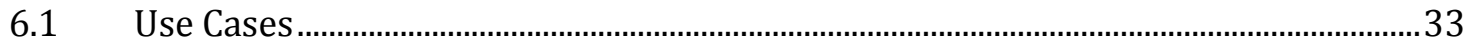

6.1.1 Web Application for the General Public........................................................................33

6.1.2 Web Application for Trailblazer Foundation Staff and Board Members...............36 






Chapter 7 - Conclusions and Future Work ...........................................................43

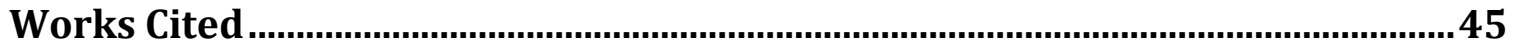

Appendix A. Application Code - Internal Use Application...................................47

Appendix B. Application Code - Public Use Application .......................................53

Appendix C. Help Documentation ..................................................................... 61 


\section{Table of Figures}

Figure 1-1: Trailblazer Foundation Reach in Siem Reap, Cambodia ......................... 2

Figure 1-2: Bio-Sand Water Filter ................................................................... 3

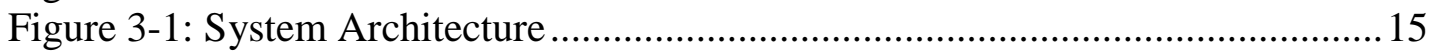

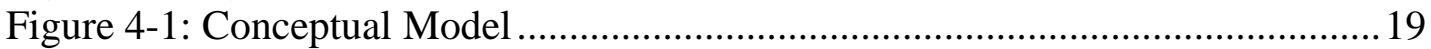

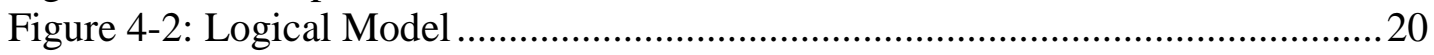

Figure 5-1: Public Use Application Map Document ............................................26

Figure 5-2: Internal Use Application Map Document ..............................................26

Figure 5-3: Application Development Workflow ................................................ 27

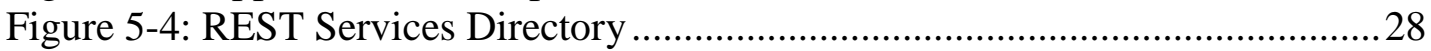

Figure 5-5: Public Use Application Model .............................................................. 30



Figure 5-7: Internal Use Application Model..................................................... 32

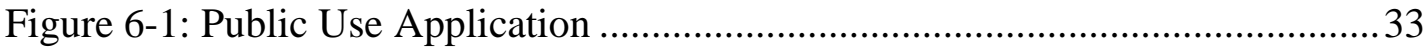

Figure 6-2: Livestock Variable ........................................................................... 34

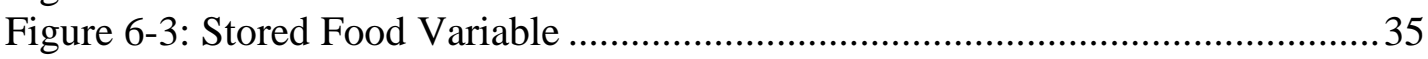

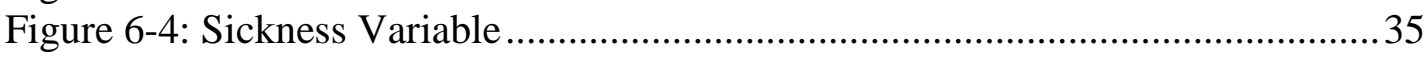

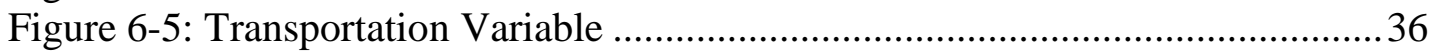

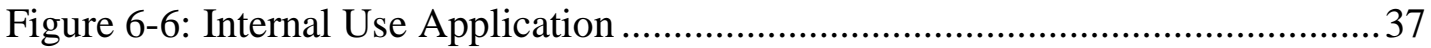

Figure 6-7: Internal Application - Search for Anonymous Donors ......................... 37

Figure 6-8: Dot-Density Map of Bio-Sand Water Filters ..................................... 38 



\section{List of Tables}

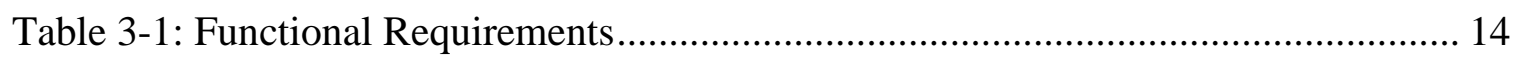



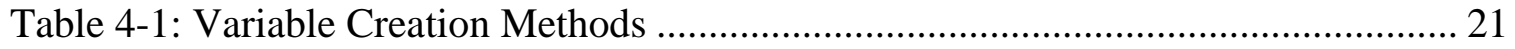

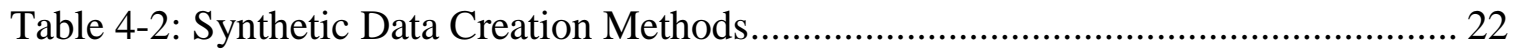

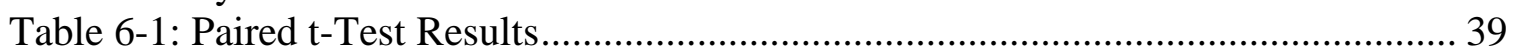

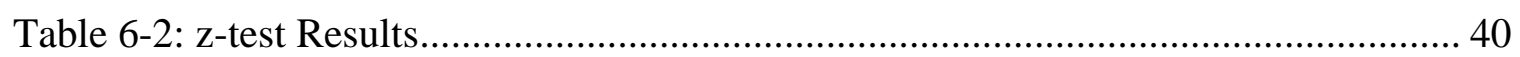





\section{List of Acronyms and Definitions}

$\begin{array}{ll}\text { TBF } & \text { Trailblazer Foundation } \\ \text { GAFSP } & \text { Global Agriculture and Food Security Program } \\ \text { API } & \text { Application Programming Interface } \\ \text { GIS } & \text { Geographic Information Systems } \\ \text { REST } & \text { Representational State Transfer } \\ \text { URL } & \text { Universal Resource Locator } \\ \text { SDK } & \text { Software Development Kit } \\ \text { IDE } & \text { Integrated Development Environment }\end{array}$





\section{Chapter 1 - Introduction}

One of the challenges faced by non-profit organizations involved in international aid and community development is creating and maintaining a good relationship with potential and current donors. The basis of this relationship is open communication of information regarding the impact the non-profit organization has with the donations it receives. This is an important issue for non-profit organizations that rely on donations to address, as it can affect future funds available to them, and ultimately the level of positive impact they are able to make in the community.

Measuring and communicating change in communities served by international aid efforts can be improved with the use of spatial and temporal information. Interactive web geographic information systems (GIS) technology can help non-profit organizations face this challenge of communicating geographic and temporal data through web maps. This report describes the development of such an application of the technology, where two web GIS applications were developed to serve the Trailblazer Foundation and help it to continue its international aid efforts in Siem Reap, Cambodia. In addition, this report discusses the methods of analysis used to measure the impact, the creation of a database to support analysis and data visualization, challenges encountered, and the design and development of the web application.

\subsection{Client}

The client for this project is the Trailblazer Foundation (TBF), a non-profit organization based in Jackson, Wyoming, dedicated to improving quality of life for rural villagers in Siem Reap, Cambodia (Figure 1-1) through sustainable development. The points of contact were Chris Coats, Executive Director and founder of the Trailblazer Foundation, and Jeni Swink, Executive Secretary and Webmaster. 


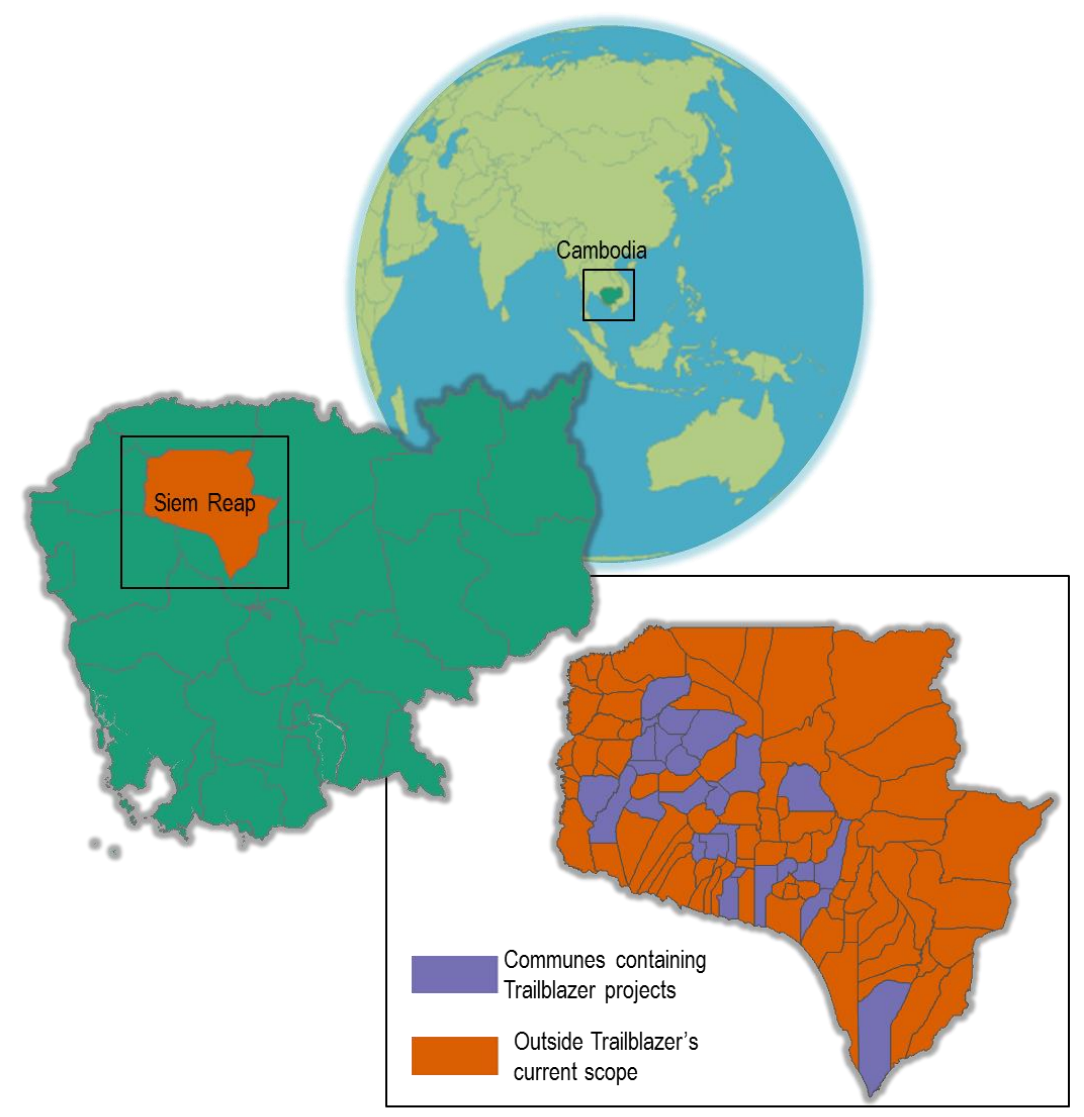

\section{Figure 1-1: Trailblazer Foundation Reach in Siem Reap, Cambodia}

Siem Reap is a province in northwestern Cambodia, and is divided into 12 districts and 100 communes. The Trailblazer Foundation has worked in 29 communes in 9 districts. According to the United Nations Children's Fund (UNICEF), 23\% of Siem Reap citizens are living below the international poverty line of $\$ 1.25$ per day, and only $65 \%$ of rural Cambodians have access to safe, clean water (UNICEF, 2011). TBF works with rural villagers, or project beneficiaries, to identify their greatest needs, and provide the necessary training, equipment, and technology to improve conditions, and primarily funds and provides volunteers to construct and install bio-sand water filters (Figure 1-2), as clean water typically is the top concern of villagers during the interviews conducted by TBF volunteers. 




Figure 1-2: Bio-Sand Water Filter

The projects are designed to be sustainable, in that TBF will eventually transfer responsibility of the projects to the beneficiaries. The long-term success of TBF depends on attracting volunteers to give their time for implementing projects as well as donors to fund the projects, and encouraging donors to give on a recurring basis. TBF wished to increase donations and volunteers by communicating to current and prospective donors the impact that TBF has in the communities through web maps accessible through its website.

To determine the impact, TBF conducts a survey to collect information about the conditions in which people that will benefit from one of its bio-sand water filters are living. After the project is implemented, TBF intends to conducts the same survey to detect changes in the lives of the beneficiaries. The surveys will be great for detecting local changes over a short period of time, but one major question TBF and its donors have is: what are the longer term effects of the projects.

\subsection{Problem Statement}

TBF wanted to be able to determine the impact of the bio-sand water filters they installed throughout Siem Reap, Cambodia on the people who were directly affected through analysis of survey data collected about beneficiaries before and after a project has been completed, as well as identify areas that require more attention. Next, TBF wanted to communicate information derived from the impact analysis to current and potential donors to encourage future donations. TBF could not effectively analyze the data collected from its projects because it was stored in several different Excel spreadsheets, 
and there were many inconsistencies in the data, as it had been entered by several volunteers in several languages. The lack of spatial context for tabular data made it difficult for TBF to visualize its data and understand how it has changed over time and compare the changes throughout the communes of Siem Reap. In addition, TBF recognized the benefit of visualizing its data spatially through the web. The Trailblazer Foundation staff hoped to solve the problem of data organization and information sharing, therefore ensuring the long-term success of its foundation.

\subsection{Proposed Solution}

The solution to the project problem is two-fold. To better recognize local variations in needs of clean water, and determine if positive a change has taken place, the survey data provided by the client were analyzed using statistical methods. Then, to communicate information to donors, a web application that shows aggregated survey data and the results of the impact analysis was built for a non-GIS audience to understand the impact their donations on the communities served by TBF. Another web application was built for the TBF staff to keep track of individual projects and donor information.

\subsubsection{Goals and Objectives}

The overall goal of this project was to provide the Trailblazer Foundation with a tool that would help to increase and diversify donations to its foundation. This was accomplished by creating a platform for TBF to share information with potential donors and encouraging current donors to continue providing resources to the foundation to carry out its mission of providing clean water to rural Cambodians, as well as for TBF staff to interact with its data spatially through visualization. The first objective was to organize the data and create a geodatabase for data storage. The second objective was to conduct spatial analysis to determine local differences between the communes and detect changes over time based on the baseline and survey data. The final objective was to create two web applications to communicate this information with TBF staff, stakeholders, and the general public.

\subsubsection{Scope}

The project scope encompassed building a geodatabase, analyzing the impact of projects implemented by the Trailblazer Foundation, and developing two web GIS applications with simple interfaces appropriate for a non-GIS audience. The geodatabase was expected to house two tables with TBF survey data in Siem Reap, one with aggregated data, and the other with individual project data. The geodatabase laid the groundwork for the development of the web applications with a user-friendly interface using the ArcGIS API for JavaScript. Data storage was provided by the University of Redlands, with the understanding that the data would be stored for only one year after delivery. TBF was responsible for integrating the web applications with their website and for all future maintenance of the final products. 


\subsubsection{Methods}

Various methods were used at each stage of the project. Frequent communication with the client was maintained during the early stages of the project to define functional and non-functional requirements. Once requirements were agreed upon, the conceptual and logical models were designed. Analysis was then conducted on the compiled survey data and synthetic data that model follow-up survey data. A paired t-Test and a difference in proportions z-test were used to test significant differences in the survey data over time. The results were mapped and published to ArcGIS Server as representational state transfer (REST) services to be consumed by the web application. The ArcGIS API for JavaScript was used to develop the web application. The Dojo Toolkit, a module for the programming language JavaScript, was essential for building the web maps and consuming the published services from ArcGIS Server using the JavaScript API.

\subsection{Audience}

This report is intended to be viewed primarily by Chris Coats and Jeni Swink of the Trailblazer Foundation, who are experts in the subject of philanthropy and the organization's work and basic understanding of GIS. This document is meant to serve as a reference for the Trailblazer Foundation staff to use as their work continues. It may be useful for others interested in implementing a web application for a philanthropic organization. The reader of this document should have a basic understanding of GIS and web development terminology and use.

\subsection{Overview of the Rest of this Report}

The Trailblazer Foundation has been providing people in Siem Reap with access to clean water without the benefits of web GIS. They recognize a need to share their story through a geographic lens. The remainder of this report discusses how the tools created for TBF were developed and implemented, and is divided into six chapters. Chapter 2 is a literature review of previous research conducted to fully understand the problem and how others have implemented a solution. Philanthropy and international aid were explored as well as a number of web applications developed in JavaScript. Chapter 3 outlines the system design and project plan, including the approach and solutions. Chapter 4 contains a description of the conceptual and logical model as well as the database design. Chapter 5 discusses the implementation process. Chapter 6 discusses the functionality of the final web application and the impact analysis results. Finally, Chapter 7 summarizes the project and this report, and discusses potential directions that could be taken to further enhance this project. 



\section{Chapter 2 - Background and Literature Review}

Access to safe drinking water is fundamental for not only a healthy life, but also education, gender equality, food security, and education. It is estimated that only $65 \%$ of rural Cambodians have access to safe drinking water, which means $45 \%$ of that population are at risk of serious health and societal disadvantages (UNICEF, 2011). This chapter discusses how Web GIS can bridge the gap between rural Cambodians in need of clean water, and generous individuals and organizations willing and able to provide the resources necessary to fulfill this important need. Section 2.1 covers the benefits of web GIS over traditional GIS applications as well as some examples of past work, and section 2.2 explores methods and best practices that were used to build the foundation of this project.

\subsection{Why Web GIS?}

Web GIS brings the technology and analysis power of GIS to the web, broadening the possibilities of GIS. Until very recently, the main focus of GIS providers and vendors has been on the basic functionality and analysis, while user experience has been an afterthought (Haklay, 2010). Traditional GIS users are limited to desktop applications and require an in-depth knowledge to use and understand the technology. So much so that there are dedicated academic degrees and professional careers devoted to carrying out and communicating geographical information. Web GIS changes that school of thought fundamentally by designing around an end user that may be experiencing GIS for the first time. "Sitting comfortably at home, you can tour the world with the click of a mouse and appreciate the high-resolution satellite imagery that makes you feel like you're right there...Web maps make a strange city as familiar as your hometown" (Fu \& Sun, 2011, p. 1). It is this familiarity that can help improve communication between people and organizations around the world. By providing a platform that can communicate information in the context of geographic location and spatial relationships to a general audience, the power of GIS is transferred from the hands of a few trained professionals to

a wide audience from a diverse background.

With advances in GIS technology, as well as ever-increasing Internet accessibility throughout the world, the use of paper maps and desktop applications as a means of communicating spatial information has become inefficient and, in some cases, obsolete. Compared to paper maps that are expensive to maintain and update, and typical desktop GIS applications that require an extensive knowledge of expensive GIS software and hardware, web GIS provides a platform on which to share up-to-date spatial information within an organization and with users who otherwise do not have access to resources required to use traditional GIS technology (Mathiyalagan, Grunwald, Reddy, \& Bloom, 2005). Expanding the community of people who can interact with GIS can have many positive effects on communities, such as increased community involvement and more efficient resource management.

While it is becoming more and more apparent that using GIS technology to manage and distribute resources in the most effective way can be very useful for organizations in the non-profit sector, it is not always cost effective. As Romalewski states, "GIS technology is not always affordable for most non-profit organizations...It's not so much 
the software, but to have at least one full-time staff person devoted to it and acquiring the data can cost" (Romalewski, 2004, p. 1). Web GIS can help to alleviate the cost that goes along with utilizing GIS technology by shifting focus from pure breadth of functionality to the end user experience, especially in terms of accessibility. Stephen Romalewski recognized the unique need for GIS in the non-profit sector and the great good that can come from efficiently managing resources and spatial data over the web. He created the Community Mapping Assistance Program (CMAP), a program within the New York Public Interest Research Group Fund devoted to providing web GIS solutions to nonprofit organizations. The mission of CMAP is to "strengthen nonprofit, philanthropic, and public service organizations by providing affordable access to computer mapping and other data visualization technologies". Through CMAP, the New York Public Interest Research Group Fund has helped nearly 300 non-profits increase their resources and optimize resource allocation through the use of web GIS (Romalewski, 2004).

\subsubsection{Applications of Web GIS}

The GIS literature has numerous examples of how web GIS has helped communities and organizations increase their efficiency, improve communication with stakeholders, and better manage resources. Jankowski, Tsou, and Wright (2007) found strong linkages between availability of geographic information and public participation in a project that introduced a web GIS application for the San Diego Bay Watershed (SDBW) called Common Grounds. SDBW needed to increase public participation in city planning proposals that would affect a wide range of stakeholders throughout the bay area. A web GIS application was put in place that enabled SDBW to share proposals and model possible outcomes via web maps, and then share those maps with community members and stakeholders. With the information readily available, community members could explore the plans in a geographic context from their own home and submit comments and suggestions after browsing through the possible models and proposals that were presented by the city planners, changing the way traditional town hall meetings were conducted.

One of the great benefits of web GIS is its versatility and approachability. In a study carried out by Li, Xiong, and Ou (2011), a web-based GIS was created to serve out historical sea ice information from the Canadian Ice Service (CIS) to both climate scientists and the general public. Sea ice data is important for climate science, fishing, tourism, environmental impact, and engineering studies, and while the people involved in these industries have varied GIS backgrounds, the need for the information is the same. Li. Xiong, and Ou found that the web GIS application was robust enough to allow scientists to perform complex analyses, while still maintaining enough simplicity to be understood by users with limited GIS experience. Their application enabled and encouraged people from all GIS backgrounds to explore, analyze, and visualize the data. By creating an application with functionality tailored towards a specific audience and providing data in a readily available format to scientists via the web, the cost of purchasing individual licenses for robust desktop systems is greatly reduced. In addition, the functionality of the application allowed for simplistic as well as complex views of the data, broadening the audience of the application and increasing traffic to their website and therefore increasing knowledge regarding a very important issue $(\mathrm{Li}, \mathrm{Xiong}, \& \mathrm{Ou}$, 2011). 
Loma Linda University is another example of an organization that has improved operations through the use of web GIS. Their Advanced Emergency Geographic Information System (AEGIS) is a prime example of how web GIS can make a difference in people's lives. AEGIS was designed to tackle the problem of situational awareness between hospitals, emergency vehicles, rescuers in the field, and dispatchers to improve response time within their service areas by serving out the necessary locational data to multiple users in real-time, a futile task with traditional desktop GIS technology (Fike, 2007). Providing access to the data to all parties involved greatly improved communication and increased efficiency which ultimately helped rescue operators get to disaster sites faster by allocating resources to areas in most need.

Dragicevic and Balram (2004) referenced Peng (1999) when they said that "cost effective access to baseline data is needed for effective planning" (Dragicevic \& Balram, 2004, p. 133). Their team performed research and analysis on collaborative mapping applications. During their research, they developed the Web GIS Collaborative Spatial Delphi Framework (CSDF) to connect with stakeholders in various planning projects and found that creating a space for stakeholders involved with various projects to interact with baseline data and that is accessible to a wide audience was the most effective way to communicate and collaborate with new stakeholders. Projects that used the CSDF application found that issues of equity among stakeholders were addressed and accountability of planners to stakeholders was increased by providing stakeholders with an avenue in which to keep planners accountable through collaborative mapping over the web.

Communication with stakeholders and potential donors is vital to the longevity of nonprofit organizations. Donations are what drive international aid, defined by Overton (2013) as a "development tool that has been utilized in order to promote wider social, economic, and political objectives ostensibly for recipients, but also for donors" (Overton, Murray, \& McGregor, 2013, p. 116). In the case of the Trailblazer Foundation, the "wider social objective" is to provide clean water to a population in Cambodia who is suffering from the effects of limited access to safe water sources. Having an understanding of how water is used and where it comes from, as well as which sections of the population do not have access to water is critical in solving the world-wide water crisis (Gleick, 1998). Overton also emphasizes that donors to international aid organizations are just as important to the institution as the recipients. Recognizing this and rewarding the efforts of donors by showcasing the positive impacts they have had in the lives of those they have provided for is an essential part of promoting the wider social objectives.

\subsection{Optimizing Web GIS}

New information is best learned when it is related to something already understood. Web GIS provides the benefits of linking spatial and non-spatial data by putting spatial data in the context of something users already know. This creates a richer user experience that is interactive, easy to understand, and even fun to learn and use (Kraak, 2004). Web GIS applications that overlay content from several web resources and GIS services are referred to as mashups (Fu \& Sun, 2011). These mashups consist of elements such as basemaps and operational layers. Basemaps are maps designed to give geographic context to information often found in the form of operational layers, which are 
representations of information derived from spatial data. Oftentimes tools such as routing, place finders, pop-ups containing additional information, searching, and editing tools are included for an interactive user experience (Fu \& Sun, 2011). In this way, web GIS can be a useful tool for communicating complex geographic information to a wide audience.

Designing a web GIS application appropriate for a general audience without an indepth knowledge of GIS requires careful selection of functionality. The specific needs and experience levels of the end users need to be taken into consideration during the design phase of the web GIS application to ensure the best possible user experience (Kraak, 2004). Certain design techniques and best practices can be used to get the most out of web GIS applications. There are three main components of web GIS - the programming language, graphics renderer, and data store. The programming language is used for coding and data retrieval device. The graphics renderer displays data on the Web in real-time and can be manipulated to display information in ways that are appropriate for the intended audience, much like cartography for traditional GIS professionals and map makers. The data store publishes data to the Web for query, enabling such functionality as querying for specific info and filtering what is on the screen to what is appropriate for the audience to see, based on search criteria and accessibility (Peng \& Zhang, 2004). The integration of all three components leverages the full potential of web GIS.

The choice of a programming language can have a huge impact on the performance and user experience of web GIS. There are several programming languages, the most popular being Flex, Silverlight, and JavaScript (Fu \& Sun, 2011). While Flex and Silverlight can offer a rich user experience and a variety of functionality, JavaScript has the ability to reach a wider audience due to its widespread use across web browsers including Firefox, Google Chrome, Internet Explorer, Safari, and is accessible through mobile devices, while still maintaining interactive properties of the applications. While there is no one scripting language that is markedly superior, JavaScript has become the preferred web programming language due to this versatility (Wilton, 2004). The first iteration of Loma Linda's AEGIS was implemented using ArcServer and generic ArcGIS Online tools. The second iteration utilized the ArcGIS API for JavaScript which offered a better user experience and more expressive applications, which enhanced the user experience (Fike, 2007). This is because the JavaScript API loads data dynamically using AJAX technology, which increases symbology options and provides a smoother looking application that can be customized to meet specific needs of users (Fu \& Sun, 2011).

The lifeblood of a web GIS is the geodatabase, as it stores and organizes the data with which the application interacts. Choosing a geodatabase design depends on the needs of the end users and the client responsible for maintaining and updating the data. There are three types of geodatabases provided by Esri, that each serve very different purposes and design requirements: personal, file, and ArcSDE. The personal geodatabase is limited by size -2 gigabytes - and allows only one editor at a time (Zeiler, 2010). The file geodatabase is virtually unlimited in size "by using an efficient data structure that is optimized for performance and data storage" (Zeiler, 2010, p. 9). ArcSDE allows for unlimited storage and versioning, as well as the ability to have multiple editors at one time, making it ideal for Web editing, such as Jankowski's Common Grounds project, and enterprise level GIS systems. For applications such as the ones built for TBF that do 
not require multiple editors or need to enable public comment, the file geodatabase is the best solution (Zeiler, 2010).

\subsection{Summary}

Web GIS has proved to be the best way to analyze and communicate complex geographic and temporal information to a wide audience with very little knowledge of GIS. The intended end users of this project have little to no GIS experience, so a Web GIS application was designed to present the client's information to a more general public. The file geodatabase was chosen because online editing was not required. However, this database design allowed for offline editing by multiple users, which is ideal for the client since they operate in several locations at once.

The JavaScript API was chosen to broaden the number of users able to access the application because it works in all browsers, does not require a plug-in, and works on mobile devices and tablets. The next chapter discusses the specific requirements and design specifications chosen for the application. 



\section{Chapter 3 - Systems Analysis and Design}

This chapter examines the planning and design phases of the project and elaborates on the specific requirements of the Trailblazer Foundation (TBF). Section 3.1 restates the problem addressed in this project. Section 3.2 discusses the requirements analysis and functional and nonfunctional requirements. Section 3.3 outlines the system design. Section 3.4 discusses the project plan as well as the evolution of the project from the original plan to the execution.

\subsection{Problem Statement}

The Trailblazer Foundation needs to be able to effectively measure the effects of its work and communicate that information to stakeholders. In addition, TBF needed to be able to identify areas which have the greatest need of their aid. The previous data organization methods were not conducive to such needs. This project aims to solve these problems through web GIS.

\subsection{Requirements Analysis}

The overarching requirement for this project was to provide $\mathrm{TBF}$ with a platform to interact with, analyze, and share its data between the organization and with their stakeholders such as current and potential donors. A requirements analysis was conducted to gather all requirements of the client. The requirements broke down into functional and nonfunctional requirements.

\subsubsection{Functional Requirements}

The functional requirements, summarized in Table 3.1, were identified based upon the user experience from the perspective of both the client using the application for planning and advertising purposes, and of its donors using it for exploration and educational purposes. 


\section{Table 3-1: Functional Requirements}

\begin{tabular}{|l|l|}
\hline Requirement & Description \\
\hline Internal Use Application & $\begin{array}{l}\text { Application for TBF staff to view } \\
\text { and query data }\end{array}$ \\
\hline Public Use Application & $\begin{array}{l}\text { Application for general } \\
\text { public/potential donors to view TBF } \\
\text { work }\end{array}$ \\
\hline Statistical analysis & $\begin{array}{l}\text { Analysis that compares areas } \\
\text { affected by client vs. areas not } \\
\text { affected by client }\end{array}$ \\
\hline Identify tool & $\begin{array}{l}\text { Allow the user to identify features } \\
\text { and view attribute information }\end{array}$ \\
\hline Preset extents & $\begin{array}{l}\text { Provide the user a quick and } \\
\text { straightforward way to zoom in } \\
\text { preset extent on study area }\end{array}$ \\
\hline
\end{tabular}

Accessibility to the data was of concern to the client, as some sensitive information regarding project beneficiaries and donors was not appropriate for public viewing. One requirement of the web application was to organize the data in such a way that showed the impact of bio-sand water filters in the community at the commune level rather than at the individual level, and limit the public to view a small subset of the data that the client has deemed appropriate. At the same time, TBF staff needed access to individual project data. Because of this, it was decided that two applications would better serve TBF's requirements of compartmentalizing sensitive information - the public use application and the internal use application. Within public use application, a public user can gain information about projects TBF has completed in the various communes without revealing individual information. The internal use application on the other hand allows the user to access and query individual project information, including project location, the name of the donor that funded each of the projects, and individual survey results for the projects, based on donor name, year the project was completed, and all projects to date.

\subsubsection{Nonfunctional Requirements}

The nonfunctional requirements were an important aspect of the project planning, as they played an important role in defining how the application works as well as the success of the project during the development and implementation phases. Nonfunctional requirements refer to tools and methods essential to achieving the goals and objectives of the project. Table 3.2 summarizes the nonfunctional requirements. 


\section{Table 3-2: Nonfunctional Requirements}

\begin{tabular}{|l|l|}
\hline Requirement & \multicolumn{1}{|c|}{ Description } \\
\hline Intuitive User Interface & $\begin{array}{l}\text { Easy for users of all levels of GIS } \\
\text { experience }\end{array}$ \\
\hline ArcGIS Online & $\begin{array}{l}\text { Supported web maps and allowed for } \\
\text { interaction with data }\end{array}$ \\
\hline Data Organization & $\begin{array}{l}\text { Organize and store data, optimized } \\
\text { for the Web }\end{array}$ \\
\hline
\end{tabular}

The user interface needed to be simple and straightforward enough for a non-GIS expert to understand how to use the application with ease. To publish feature services to the web, the use of ArcGIS 10 or later was required. Version 10.1 was used for this project. The data needed to be organized in a way that was optimized for web publishing, which was accomplished through the creation of two map documents within ArcMap 10.1. ArcGIS Online served the data and the application to the web. Finally, TBF required storage of the data associated with the applications, but was not ready to purchase the storage through ArcGIS Online until they knew the application would serve the purpose of increasing and diversifying its donations as well as improve data analysis. Therefore, the data were stored on the University of Redlands server with the agreement that after one year the data would need to be transferred TBF to its own servers.

\subsection{System Design}

A network of hardware and software was designed to accommodate client's needs and system requirements. This design is illustrated in Figure 3-1.

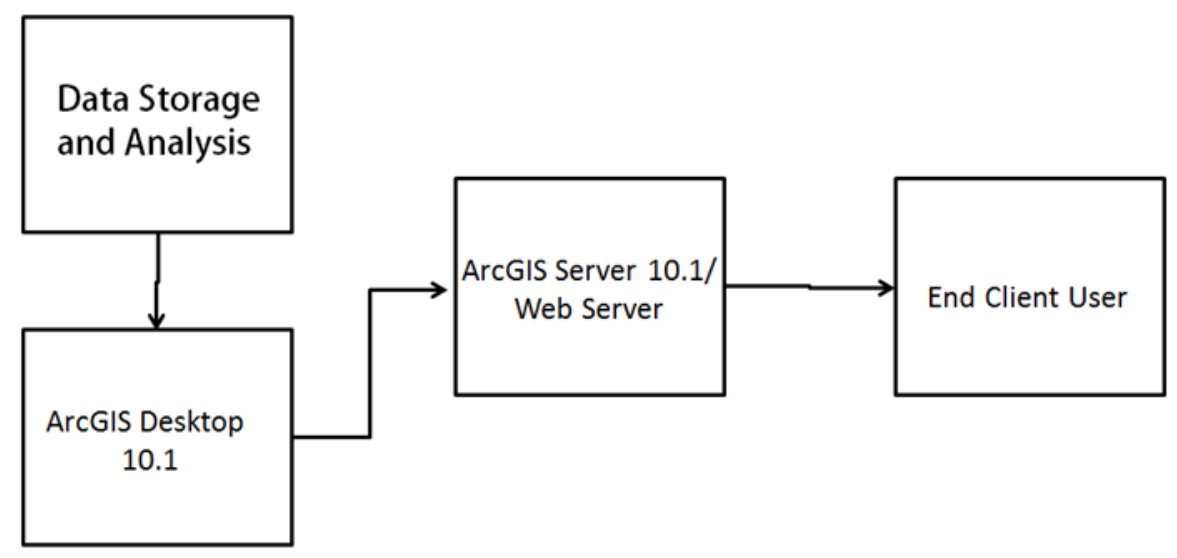

Figure 3-1: System Architecture 
The main components of the system architecture included a file geodatabase for data storage and analysis, ArcGIS Desktop for publishing feature services, ArcGIS

Server/Web Server for hosting feature services and application, and the end client that consumes the web application. Figure 3-1 depicts the project's system architecture.

\subsection{Project Plan}

The initial project plan included the following stages: requirements analysis, data organization, database development, statistical analysis, map creation, web application development, and implementation. Several major changes to the plan were made as the project developed to ensure completion of the project within the given period while still fulfilling the client's expectations. A web application was agreed upon from the start. The Trailblazer Foundation had a vision of sharing the impact of its work with current and potential donors through a web map accessible via its website; however during the requirements analysis it became clear that two applications would serve its needs better than one because the general public and the TBF staff had very different requirements and questions to ask of the applications.

The next step in the process was data organization. Originally the plan was to measure the impact the client has on the ground by comparing the results of surveys taken on site before a project is implemented with the results of the same survey taken at the project location 3-5 years after project completion, as this is the process in which they collect their survey data. However, since the available datasets did not include follow up surveys yet, another plan was needed to resolve the issue. Historical data of past projects was not available for use in this project, as it was stored in several locations, some of which were not digital, rendering them incompatible with the web application at this time. Ultimately it was decided that the best course of action for the project plan was to create a proof of concept with synthetic follow up survey data holding the place of the actual survey data until the follow up surveys for the projects represented in the applications are conducted.

Once the data had been collected and organized, the geodatabase was to be created and optimized for the web. The geodatabase was designed to hold the survey data and the commune boundary data. Symbology and labels were also added to the geodatabase. The geodatabase was then ready to allow for statistical analysis. The paired t-Test and difference in proportion z-test were chosen to conduct the required analysis, and the results of the statistical analyses were stored inside of the geodatabase as well.

Two map documents laid the groundwork for publishing the data via ArcGIS Server, which then allowed the web applications to be developed. Each application used its data service, set up within the map documents. The applications were then developed based upon the requirements gathered during the requirements analysis, and finally implemented by serving the applications out to the web via ArcGIS Online. The final deliverables were delivered to the client as .html files to allow them to implement the applications on their website as they wish. 


\subsection{Summary}

This chapter examined the requirements agreed upon by the TBF, including both functional and nonfunctional requirements. The deliverables were discussed as well as the specific hardware and software needed to fulfill the functional and nonfunctional requirements. The project plan was discussed and the system design was illustrated to lay the ground work for the geodatabase design and web application development. This discussion leads into the next chapter, in which the geodatabase and the data used for analysis are discussed in addition to the conceptual and logical data model designs. 



\section{Chapter 4 - Database Design}

This chapter discusses the conceptual and logical models that set up a framework for the database behind the web applications. The database for this project needed to work well with the web applications. This involved organizing the data into two tables and creating synthetic follow-up data for analysis. This chapter discusses the methodology of creating the database and preparing the data for loading into an Esri file geodatabase.

Section 4.1 introduces the conceptual model on which the database was built which consists of the objects and relationships derived from the requirements analysis. Section 4.2 discusses the logical model, which expands upon the conceptual model by outlining the data associated with the elements of the conceptual model. Section 4.3 discusses the data sources and the methods used to collect data, and Section 4.4 discusses the data scrubbing and loading methods that were carried out.

\subsection{Conceptual Data Model}

The conceptual model outlines the major entities in the problem to be addressed. For this project, there are four objects that make up the conceptual model: projects, beneficiaries, donors, and surveys. Figure 4.1 illustrates these objects and their relationships.

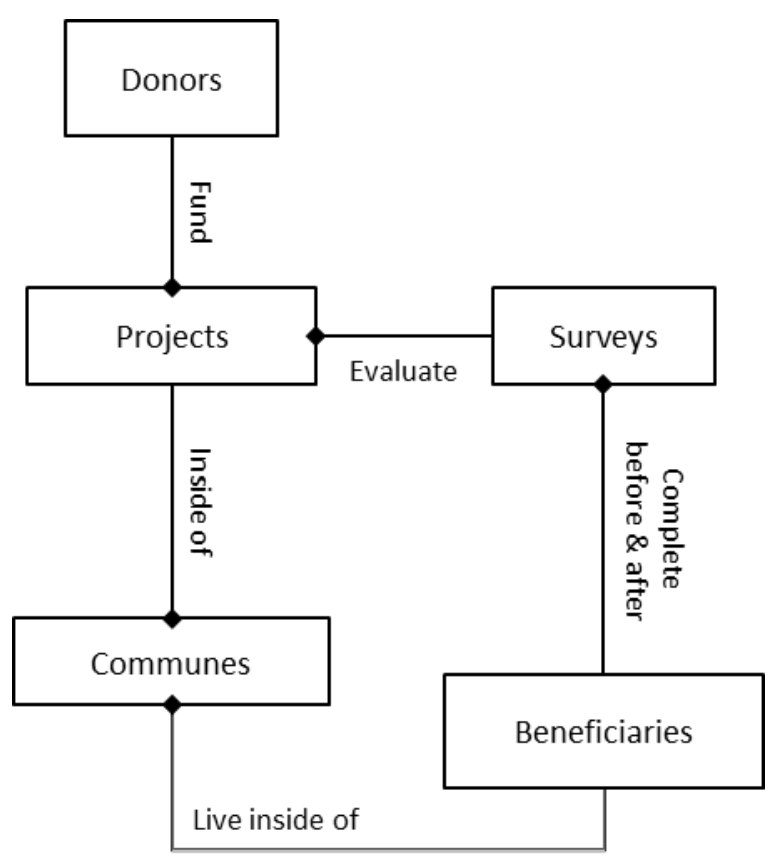

Figure 4-1: Conceptual Model

Projects refer to the bio-sand water filters installed by TBF in the communities that have been identified by TBF as needing cleaner water. This is determined through surveys of the project beneficiaries. Beneficiaries are the people living in the communities served by TBF who directly benefit from one of the projects. Donors refer to individuals and organizations who have donated money or resources to enable TBF to implement its projects. The Trailblazer Foundation keeps track of which projects the 
donors' money goes towards funding. To evaluate the influence of the projects, surveys of the beneficiaries were collected by the TBF staff. Surveys conducted before the project is implemented are baseline surveys, and surveys conducted five years after the project has been implemented are follow-up surveys. The information contained in the surveys make up the bulk of the data used to measure the impact the projects have on the lives of the beneficiaries. The baseline surveys considered for this project were conducted in 2012 and 2013.

\subsection{Logical Data Model}

While the conceptual model established the objects and relationships defined in the problem statement, the logical model represents the data associated with those objects and relationships as they relate to the database. The logical model is illustrated in Figure 4.2 .
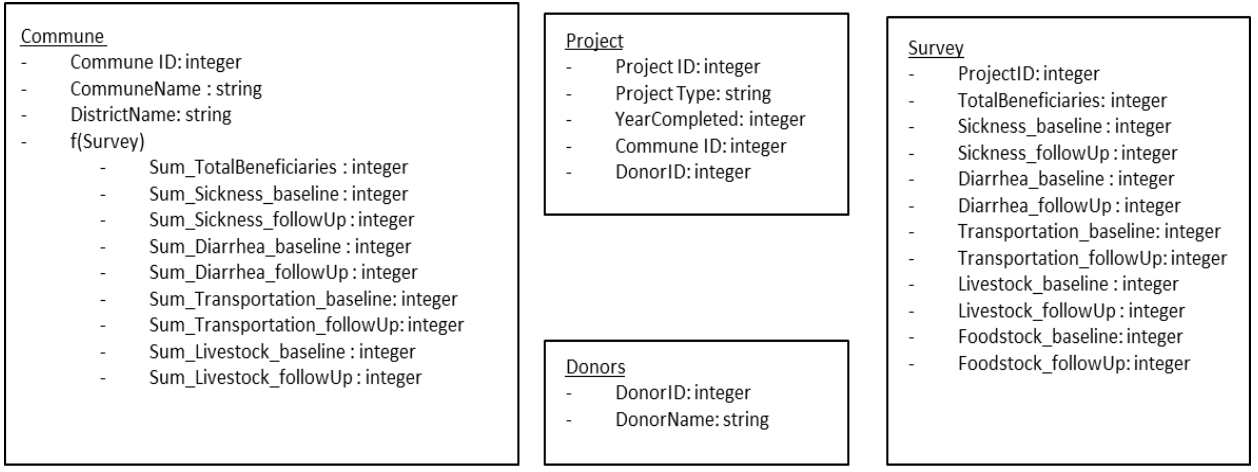

Figure 4-2: Logical Model

The survey table contains information regarding the baseline and follow-up survey results for each variable contained in the survey, as well as the total number of beneficiaries involved in the project. In the survey table, one line represents one project. The project table contains information regarding the project type, location information, donor name, and the year the project was completed for each individual project. The commune table contains the aggregated survey data at the commune level. The sum of the number of projects in each commune was calculated, along with the sum of the survey results associate with those projects occurring in each commune. The survey results found in the commune table are a function of the individual survey results found inside the survey table. The donor table contains information regarding the individual donor names that are associated with each individual project. This data organization would ultimately enable creating the map documents and publishing the feature services.

\subsection{Data Sources and Collection Methods}

The primary data for this project came from the survey data collected by TBF volunteers at the time the bio-sand water filters were installed, along with information regarding the bio-sand water filters including location, donor name, and the year the project was completed. All baseline survey data associated with TBF were provided directly by Chris 
Coats, the Executive Director of TBF. The datasets were in the form of Excel spreadsheets containing baseline survey data along with other information pertaining to projects completed between January 2012 and July 2013. Boundary data was also used to represent the communes and provide a frame of reference for the web application. The boundary data used for this project were obtained from the Global Agriculture and Food Security Program (GAFSP).

\subsubsection{Survey Data}

The survey data contained fifteen questions that were related to quality of life of the beneficiaries (Table 4.2). The fifteen questions were then lumped into five categories transportation, livestock, stored food, and sickness. The sickness variable was grouped with the diarrhea variable for the purposes of the web application, which is discussed in section 6.1.

Table 4-1: Variable Creation Methods

\begin{tabular}{|l|l|l|}
\hline Variable & Code & Survey Questions \\
\hline Transportation & $\boldsymbol{X}_{\text {transport }}$ & $\begin{array}{l}\text { Number of Bicycles, Number of } \\
\text { Motorcycles, Number of Trucks, and } \\
\text { Number of Oxcarts }\end{array}$ \\
\hline Livestock & $\boldsymbol{X}_{\text {livestock }}$ & $\begin{array}{l}\text { Number of Chickens, Number of Ducks, } \\
\text { Number of Cows, Number of Buffalo, } \\
\text { Number of Pigs, Number of Fish Ponds }\end{array}$ \\
\hline Stored Food & $x_{\text {food }}$ & $\begin{array}{l}\text { Rice Stored(kg), Vegetables Stored(kg), } \\
\text { Fruit Stored(kg) }\end{array}$ \\
\hline Sickness & $\begin{array}{l}\boldsymbol{X}_{\text {sickness }} \& \\
\boldsymbol{X}_{\text {diarrhea }}\end{array}$ & $\begin{array}{l}\text { Presence of Diarrhea in family, Presence of } \\
\text { Other Sickness in family (yes or no) }\end{array}$ \\
\hline
\end{tabular}

These survey questions are asked of the main point of contact for each project, and pertain to all the beneficiaries of the bio-sand water filter, which ranges from 1 to 100 beneficiaries per project. The follow-up survey is conducted five years after the project has been completed, and the same questions are asked of the same people. The variables were created to aid in the analysis as well as to present the information to the general public in a way that made sense. $X_{\text {transport }}$ is the sum of vehicles available to the beneficiaries: bicycle, motorcycle, truck, or ox cart. $X_{\text {livestock }}$ was derived as a sum of the total number of chickens, ducks, cows, buffalos, pigs, and fish ponds. $T_{\text {food }}$ was calculated by taking the sum of the measured amount of rice, vegetables, and fruit the beneficiaries had in storage. $X_{\text {sickness }}$ and $X_{\text {diarrhea }}$ was originally recorded as "yes" or "no", and for purposes of entering into the database, "yes" was represented as 1 and "no" as 0. The sickness variable is a combination of the presence of diarrhea and the presence of other sickness. These variables were combined for design purposes to optimize the web application.

For the purposes of this project, since TBF does not plan to conduct the follow-up surveys for these projects for another five years, synthetic data (Table 4-2) was created 
that resembled the kind of data TBF can expect to collect when the time comes, around 2018, to conduct the follow up surveys.

\section{Table 4-2: Synthetic Data Creation Methods}

\begin{tabular}{|c|c|c|}
\hline Variable Code & Type & Steps Taken to Create Follow-Up Survey Data \\
\hline $\begin{array}{l}\bar{X}_{\text {transport }} \\
\bar{X}_{\text {livestock }} \\
X_{\text {food }}\end{array}$ & Continuous & $\begin{array}{l}\text { A random number between } 0 \text { and the minimum } \\
\text { observed value was added to the baseline data }\end{array}$ \\
\hline$T_{\text {sickness }}$ & Binary & $\begin{array}{l}\text { The proportion of the population that answered yes } \\
\text { in the baseline survey was calculated. A } \\
\text { percentage lower than the baseline percentage } \\
\text { was then selected within SPSS and assigned a } \\
\text { value of } 1\end{array}$ \\
\hline
\end{tabular}

The synthetic data were loaded into the database in place of actual follow up data. While this had no effect on the design of the database, it is important to keep in mind that the database is a proof of concept, relying on the assumption that the follow up survey data will resemble the baseline survey data.

Using IBM's SPSS Statistics software program, four new variables were generated for each individual project to represent transportation, sickness, livestock, and stored food after the projects were completed. To show an outcome of an overall positive impact on the ground, it was decided to show an increase in the transportation, livestock, and stored food variables, and a decrease in the sickness variable. To create the follow up survey results of the sickness variable, twenty percent of the cases were randomly selected to show a decrease in the presence of sickness, while the remaining eighty percent of cases showed no change. The follow up survey for the remaining three variables (transportation, livestock, and stored food) were generated by first determining the range of values within the original baseline survey. Based on that range, a random number between 0 and the minimum value was added to the baseline value. The synthetic data were included in the web application, with the intention of showing what can be done with baseline and follow up survey data.

\subsubsection{Commune Boundary Data}

Commune and district boundary data were obtained from the Global Agriculture and Food Security Program (GAFSP) derived from World Bank boundary data and downloaded from an ArcGIS Online service published by its organization. This dataset was loaded into the geodatabase and joined with both the aggregated and individual project tables on the basis of commune name. All data related to the beneficiaries, projects, and surveys used in this project were collected by TBF through interviews with beneficiaries of its projects. A dataset containing boundaries of communes and districts within Cambodia was collected by GAFSP and downloaded for the purposes of this project via ArcGIS Online as a feature service. Communes and districts within Siem Reap were clipped out of the original GAFSP dataset for use in the database for this project. 


\subsection{Data Scrubbing and Loading}

Before the data were ready to be loaded into the database, some scrubbing methods were performed to ensure a smooth loading process and to optimize the performance of the published data services as well as the web applications. The first step was ensuring that all projects could be located on the map. Most projects contained spatial information in the form of XY coordinates, while some for some projects the only spatial information was the project and district name in which the project was implemented. Project records that contained no spatial information were omitted from the final table that was loaded into the geodatabase because they could not be located on the map. Then, attribute fields that contained no data were deleted to reduce unnecessary columns in the database. Entries that were left blank in place of a zero were assigned a value of 0 , and a spell checker was run on the data to ensure all words were spelled consistently. This was of concern because the data were entered by several different volunteers throughout the years, and several spelling inconsistencies and extraneous spaces were fixed prior to loading into the database.

The data were then added to ArcMap 10.1 as an XY event, with the spatial reference WGS 1984. Then, the Project tool was used to re-project the data into Web Mercator. This projection was chosen due to its wide use among web applications, and because the analysis of the data did not depend on an equal area or equidistant projection. Next, the GAFSP commune boundary data were added to the database, and a spatial join was performed to link the project data with boundary data. This was necessary to create the aggregated dataset, which is discussed in section 5.1.

\subsection{Summary}

The database design was discussed in this chapter. The conceptual model introduced the major players and relationships. The logical model outlined the data required of each object inside the conceptual model. These models were the framework for the final database design. The data preparation methods were also discussed here, and the creation of the four variables used to detect change in the survey data over time and between the communes. The next chapter discusses the implementation of the database. 



\section{Chapter 5 - Implementation}

A web application was designed and implemented to view, query, and share Trailblazer Foundation (TBF) data for the public users, donors, and the internal staff. This chapter will outline the steps taken to complete the web application. Section 5.1 discusses the development and implementation of the geodatabase. The development of the web applications is discussed in section 5.2, and the functionality of each application is covered in section 5-3.

\subsection{Geodatabase Development}

The development of the geodatabase was the first phase of the project implementation, as it provides a framework for the web applications. As discussed in Section 4.5, four indicators, including number of transportation options ( $\left.T_{\text {transport }}\right)$, amount of stored food $\left(X_{\text {food }}\right)$, number of livestock $\left(X_{\text {livestock }}\right)$, and number of family members suffering from diarrhea or other sickness ( $X_{\text {sickness }}$ and $\left.X_{\text {diarrhea }}\right)$, were used to analyze the impact of these projects on the local communities. The impact analyses were intended to compare the surveys conducted before and after the projects in the communities. When follow-up survey was not available, synthetic survey data were created for proof of concept. The synthetic survey data should be replaced by the follow-up survey when they are available.

After creation of the synthetic data, the individual project data were aggregated at the commune level to protect the identity of the individual beneficiaries and donors and to make the data more approachable for a user with little to no GIS experience or prior knowledge of TBF. This data was used to create the map document that later became the feature service used in the public use application. The individual data were used to create the internal use map document and application.

In the final geodatabase, one table named "TrailblazerProjects" contains point data where one point represents one project. The attributes of "TrailblazerProjects" include results of the baseline and synthetic follow-up survey on the individual project level, as well as the name of the donor that funded the particular project. The other table, named "TrailblazerCommuneSurveys", contains polygon data with data summarized at the commune level. Each polygon contains attributes that concern the aggregated survey data derived from the individual survey data. The polygon layer was created by joining the Global Agriculture and Food Security Program (GAFSP) country boundary dataset acquired from ArcGIS Online through a spatial join based on project location. The "TrailblazerProjects" table was imported into ArcMap using the Make XY Event Layer tool. Since the original data did not include a spatial reference, the points were loaded into the software using WGS 1984, and then the Project tool was used to project the data into Web Mercator, which is the most appropriate projection for publishing the service to the Web due to its wide use across platforms. Upon loading the point data into the database, it was revealed that some of the points did not appear in the correct part of the Siem Reap province due to errors during data collection. To correct for this issue and ensure that all projects have correct location, the points were edited and manually moved within the map document to the correct commune to ensure all projects appeared in the 
appropriate location in the final application and to ensure the spatial join performed to create the aggregated data table was correct.

Once the two tables were loaded into the database, map documents for the application were designed and prepared for publishing, one for the public application shown in Figure 5-1 and the other for TBF internal use shown in Figure 5-2.

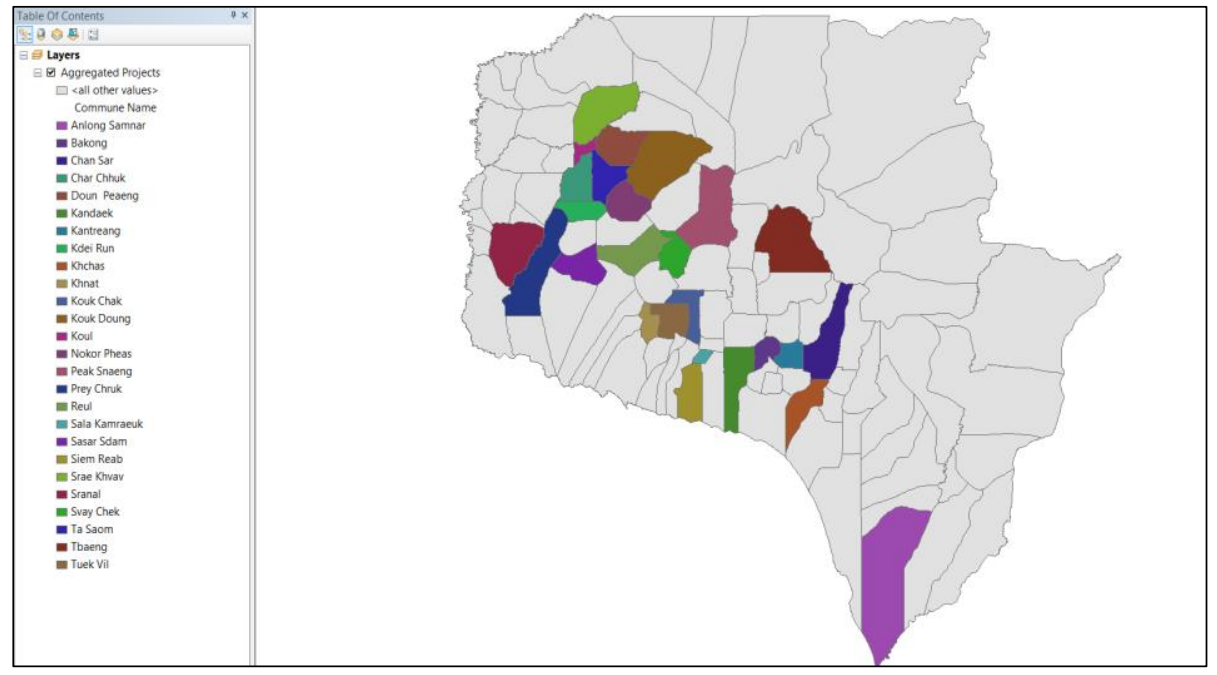

Figure 5-1: Public Use Application Map Document

The public application accesses the "TrailblazerCommuneSurveys" table (Figure 5-1). Each polygon represents a commune within Siem Reap, and the colors were chosen to differentiate communes that contain TBF water filters from those that do not. The communes that do not contain TBF projects appear in grey. This design laid the groundwork for the web application and info templates that would relay information to the public.



Figure 5-2: Internal Use Application Map Document 
Figure 5-2 shows the internal application that accesses the "TrailblazerProjects" table. This map was designed to allow TBF staff to query the database based on specific project information and visualize the locations of specific projects based on specific search criteria. Each point represents one project. This map includes Esri's "Gray" basemap to give context to the points. All of the projects are shown on this map, and they are symbolized based on donor name - each donor name was assigned a different color.

\subsection{Web Application Development}

Once the ArcGIS map documents (.mxd) were completed, they were ready to be published to the Web. Figure 5-3 summarizes the workflow that was followed to create the web application, which includes publishing web services, developing web interface and functionalities, debugging and testing, and deploying the final application.



Figure 5-3: Application Development Workflow

This process was repeated twice, one time for each application. The following sections discuss these steps.

\subsubsection{Developing a Web GIS}

To achieve all of the benefits that web GIS can offer, the right design is essential. There are a wide variety of options - interface, analysis, and functionality - that enhance the overall user experience (Adnan, Singleton, \& Longley, 2010). These elements are best implemented in a web GIS application using an application programming interface (API), which is based upon a specific programming language. The choice of API depends on the preferences and requirements of both the programmer and the user. APIs come in a variety of styles and languages, the most popular and accessible being Flex, Silverlight, and JavaScript (Fu \& Sun, 2011).

The main benefit of using an API is that users are not required to download external software or own any special hardware, since the API communicates with the browser to display and query the data behind the scenes as the user interacts with the application. Though each API has its own advantages, the ArcGIS API for JavaScript is preferable for reaching a wider audience using a variety of web browsers and devices to access the application, while still having the ability to "accommodate sophisticated graphics and user interactions" (Fu \& Sun, 2011, p. 97). The ArcGIS API for JavaScript is based upon open-source code, and therefore does not require plug-ins and will display on mobile devices, reaching the largest number of users, as compared to Flex and Silverlight which require plug-ins and custom browser specifications (Fu \& Sun, 2011). 


\subsubsection{Publishing to the Web}

The maps were shared one at a time as separate map services in the same specified folder inside the ArcGIS Services directory within the University of Redlands ArcGIS Server account. Only Mapping and KML publishing options were chosen for the purposes of viewing and querying the map and corresponding data. Metadata was added to provide a short description of where the data came from and the restrictions on its use, such as only TBF staff have permission to use and distribute the data published within the applications.

Before publishing, the Analyze tool was used to ensure the service is error-free and ready to be published. All errors were addressed such as ensuring the data would not be copied to the server by creating a direct path using relative path names, and the data were drawing at appropriate scales of 1:750,000 and 1:24,000. Once the Analyze tool showed that the map was ready for the Web, the services were published to the server and became accessible through the Representational State Transfer (REST) interface in the ArcGIS Services directory in the folder chosen when publishing as shown in Figure 5-4.

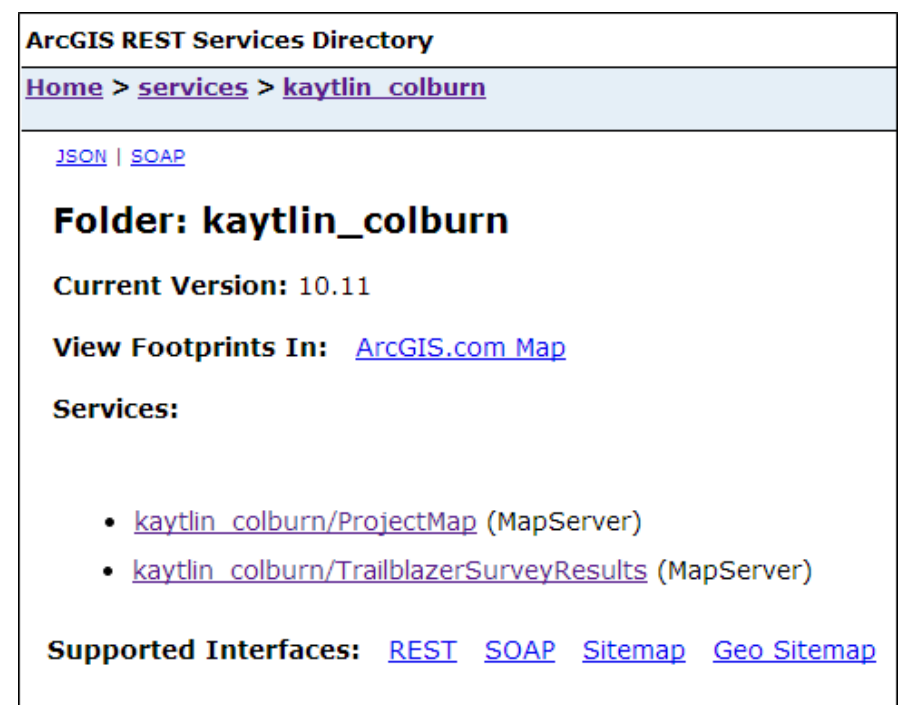

Figure 5-4: REST Services Directory

The REST services directory shows all published map services and metadata. By publishing the data in this way, it was easily incorporated into the Esri basemap with the use of the ArcGIS Application Programming Interface (API) for JavaScript. During the development of the web application when the published services are incorporated, the Universal Resource Locator (URL) that is unique to the service was used to specify the appropriate service for the application. Each of the published services contains one layer corresponding to the table from which the service was created.

\subsubsection{Developing the Web Application}

Development of the web application began once both map services were published and assigned a URL. The application was built using the ArcGIS API for JavaScript, a software development kit (SDK) used for building Internet applications that leverage 
Esri's ArcGIS Online technology with the programming language JavaScript. JavaScript is an open source programming language, meaning applications developed in JavaScript are able to run in all web browsers without the addition of extra plug-ins that the Flex and Silverlight applications require due to their closed nature as programming languages. This quality of JavaScript provides users with the ability to access the application in their favorite web browser, either via a desktop computer, laptop, mobile device, or tablet. This was critical in fulfilling the requirement of creating an easy to use application interface. JavaScript, like other web programming languages can be developed in simple text editors. However, integrated development environments (IDE) are designed to aid in the development process and enable debugging, enabling the developer to build a more robust application than if built in a text editor (van Dyk, 2010). Aptana Studio 3 was chosen as the IDE for this project. A new project was created within the Aptana Studio 3, and a local web server using Apache Tomcat was set up for the purposes of testing and debugging. Each application was coded according to the unique requirements, which are discussed in Section 5.3. Several iterations of developing, testing, and debugging took place during the development stage of the applications. Upon completion, the applications were deployed to the MS GIS web server for one year. The application was not deployed onto TBF's web server because they did not have access to the ArcGIS Server at that time, and did not want to purchase a subscription while the application is still a proof of concept.

\subsection{Functionality of the Web Applications}

As discussed in earlier sections of the report, the project originally proposed one web application for TBF to showcase its work and run analysis on its data. However, during the database design phase, it became apparent that the needs of TBF could be better met by two separate applications: one for internal use only such as TBF staff and board members; and one meant for public users to explore the work of TBF via TBF's website. Two applications better served the functionality and security of information as required by TBF, and improved upon the user experience for both types of users. The main reason was privacy. TBF wanted to keep data about individual beneficiaries, project locations, and donors out of the public eye and restricted to only TBF staff and board members, while at the same time allowing public users to get a better idea of the impact TBF and its donors have in Siem Reap.

\subsubsection{Public Use Application}

The public use application accesses the map service from the "TrailblazerCommuneSurveys" table. This application was meant to show which communes contain projects and which do not without revealing information about individuals. Simplicity was the main goal for the user interface, as the level of familiarity with the data and with GIS is unknown for users of this application. It was designed in such a way that allows for a user experience GIS for the very first time to gain something from using the application. Figure 5-5 illustrates the design of the application. 
- Number of Livestock $\bullet$ Modes of Transportation • Number Sick • Amount of Stored Food

\section{Map}

Figure 5-5: Public Use Application Model

The bulk of the information regarding the TBF projects is found in the survey data. The variables derived from the raw survey data are presented to the user to explore changes over time and space. Radio buttons at the top allow the user to look at one variable result at a time. Users can switch between variables as they like by selecting the radio button of the variable they want to explore. The gray basemap was chosen to match the style of the final map document. The zoom level is set to show all of Siem Reap upon opening the application, though users are able to zoom in or out as they like once the page has loaded. A help document is included with the page to provide guidance on navigating the application.

Four info template windows were designed (Figure 5-6) to allow the user to view the four aggregate variables (transportation, livestock, stored food, and sickness) at the commune level. The selected radio button determines which info template window that appears when the user clicks on one of the communes on the map of Siem Reap. 


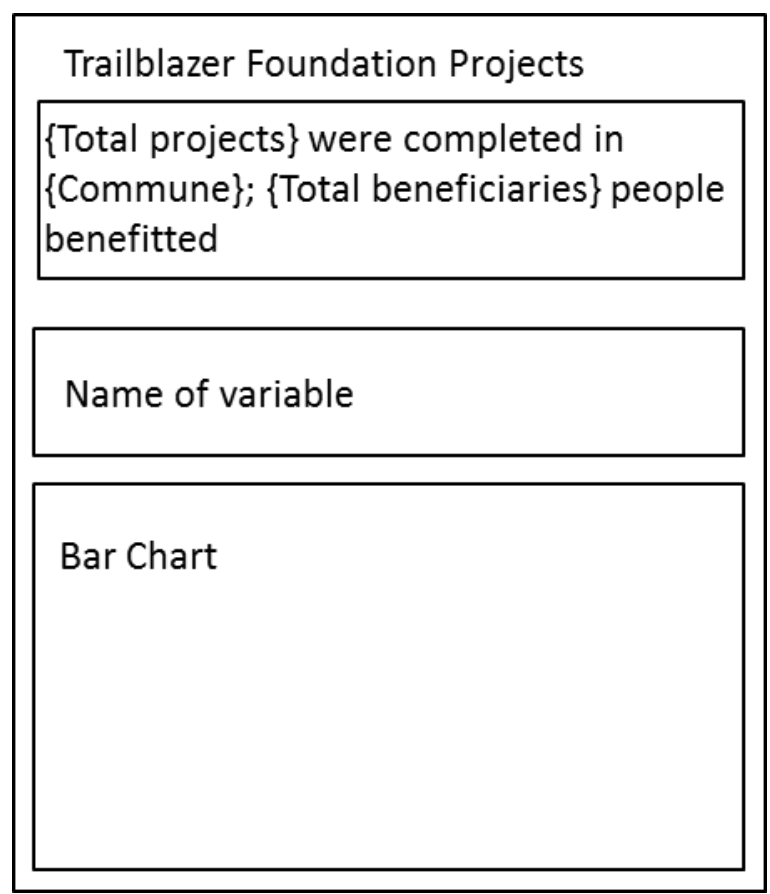

Figure 5-6: Info Template Window

Each info template contains a bar chart that shows the sum of each variable obtained in the baseline survey and in the follow-up survey with the selected commune. A bar chart was chosen as a simple way to visually compare the changes over time in the lives of the project beneficiaries in terms of the surveys conducted by TBF. There are four versions of the info templates, one for each variable to simplify the application and meet the requirement of an easy user experience with a public user in mind. The info templates used in this application were found in the Dojo library and were customized for each variable. The field name within the geodatabase and service is called inside the info template to specify which field to pull the information from. Some language describing the variable was added, as well as information regarding the number of projects and the number of beneficiaries using the same method.

\subsubsection{Internal Use Application}

The application meant for internal use within TBF calls upon the "TrailblazerProjects" service containing point data and survey information for each individual project. The main goal with this application was to provide a tool for TBF staff to interact with its data spatially to gain a better understanding of where its donor money has been spent and what kind of impact its individual donors are having in the various regions of Siem Reap. This is achieved through an interface that enables query of the data by donor name and year the project was completed, which is illustrated in Figure 5-7. 


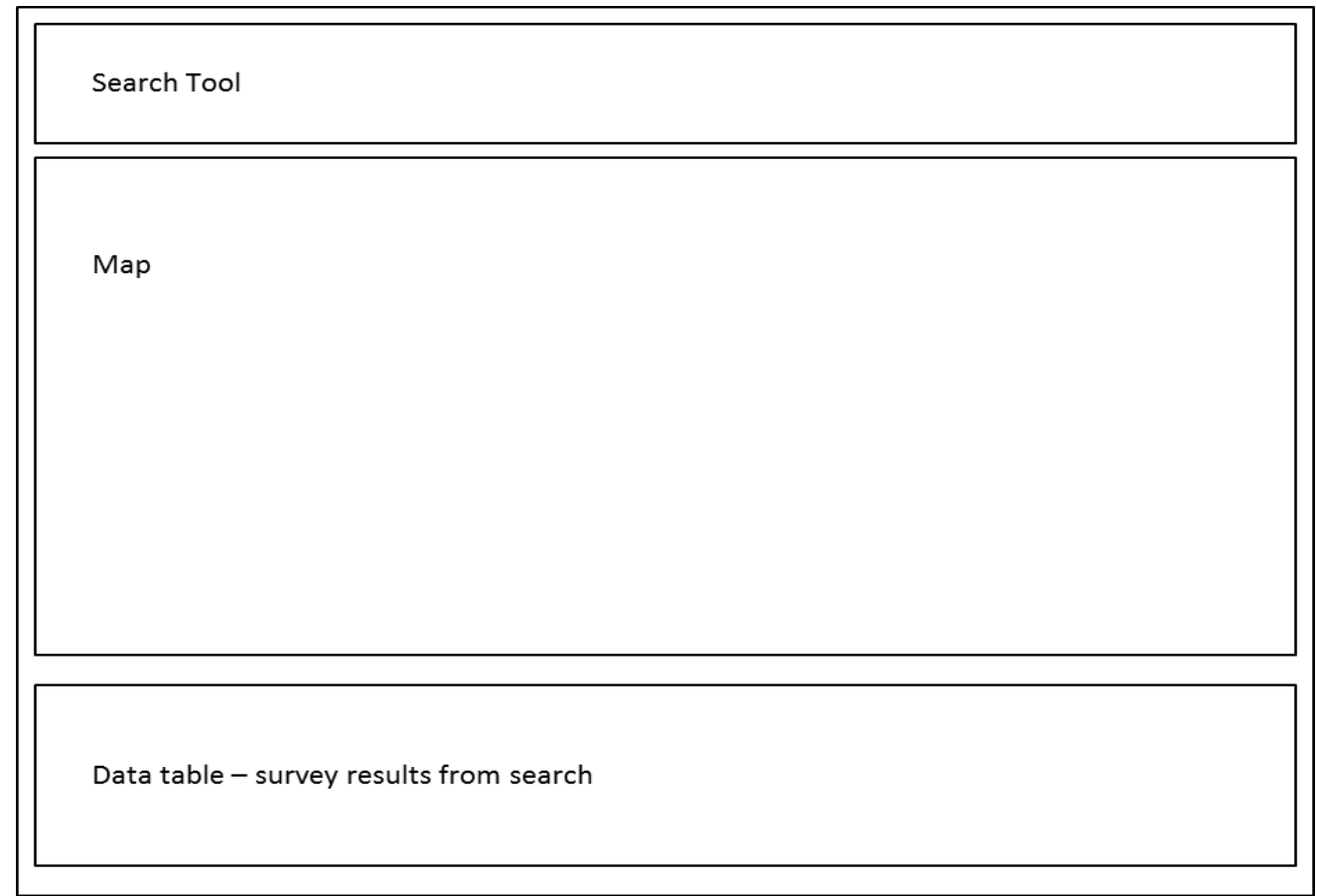

Figure 5-7: Internal Use Application Model

The application allows the user to search for any donor name or year using the search box at the top of the application. The search functionality was created using the Esri "FindTask" class within the JavaScript API. This class searches through a table for records that match the criteria of the text entered in the search box. When users clicks the "Search" button next to the text box, the map populates with the points that represent the projects that match the search criteria and the table populates with information regarding those projects. Simplicity was a priority in the development of the internal use application to enable as well TBF staff and board members to navigate the application without an in-depth knowledge of GIS. The data table provides a view of the data that is similar to TBF's previous view within Excel spreadsheets, and the addition of the map allows for a visualization of how each project relates to each other spatially.

\subsection{Summary}

This chapter discussed the development of the web applications created for this project, the public use application and the internal use application. The final products provided TBF with a tool for communicating with its donors, the general public, and within TBF staff to increase and diversify its total donations. Creating these tools was accomplished by first creating a geodatabase and developing a map document that represented the data in a way that was appropriate for each type of user. Next, services were published using ArcGIS Server, which pushed the data to an online environment in a format consumable by the ArcGIS API for JavaScript. Finally, the services were called within each application and specific functionality within the API was added to create an easy to use application for the intended audience. The full code for both applications can be found in Appendix A and B. The next chapter will discuss the results of the analysis. 


\section{Chapter 6 - Results and Analysis}

This chapter presents two use cases - one for the public use application and the other for the internal use application. Section 6.1.1 discusses a use case for a user unfamiliar with Siem Reap and TBF wanting to learn about how TBF has affected the local community and make a decision on whether they want to donate to a project. Section 6.1.2 explores a use case for a user that is a TBF staff member looking for projects that have been funded by a specific donor to gain more information about the impacts of these projects, as well as where those projects are located in relation to one another. Statistical analyses were conducted to detect the changes in the local communities brought by the projects using the baseline and follow-up surveys. Results from paired t-Test and two proportion z-tests are discussed in section 6.2.

\subsection{Use Cases}

As discussed in Chapter 5, during the database design it was determined that the TBF's needs could be better met with the creation of two separate web interfaces customized for the two groups of audience meant for the application, including - the TBF staff and the general public. In this section, two scenarios involving the kinds of questions expected from the users are considered: one from a public user and the other from an internal application user.

\subsubsection{Web Application for the General Public}

The first use case considers the scenario of a person encountering TBF for the first time, and wanting to explore the impact of TBF projects on Siem Reap, Cambodia; specifically, how the lives of the beneficiaries have changed by having access to TBF's bio-sand water filters. In doing so, the user would be able to decide if he/she wants to donate to TBF by funding a project. Figure 6-1 shows what the user sees upon opening the public use application.

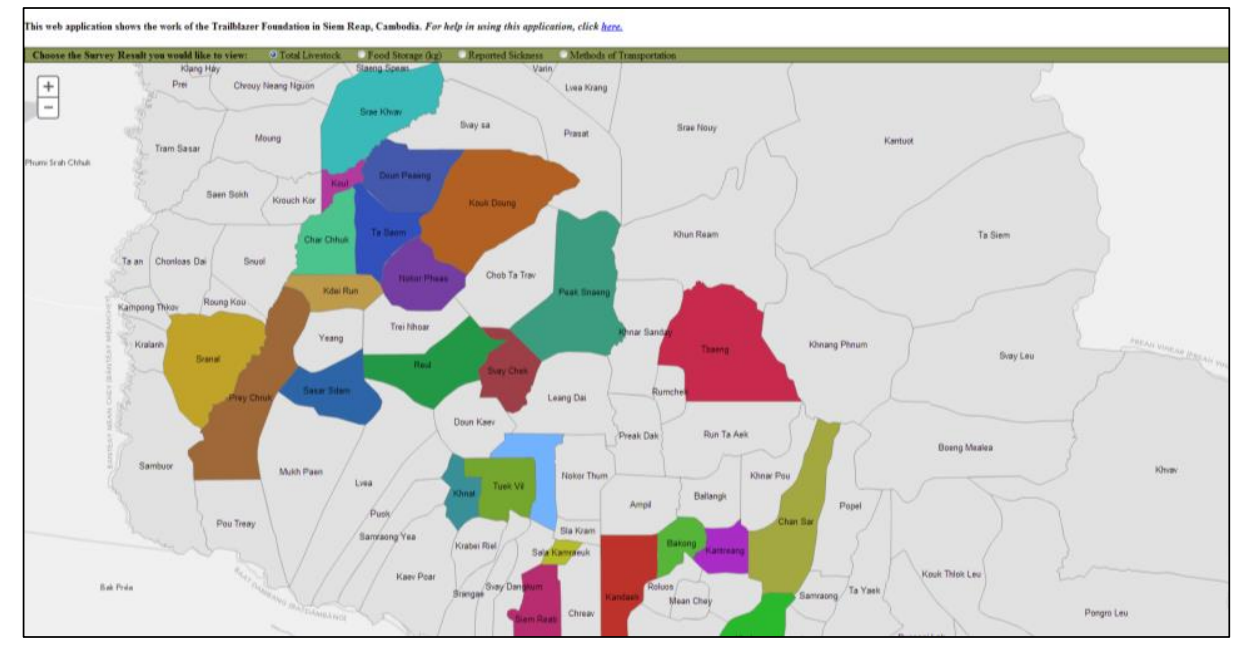

Figure 6-1: Public Use Application 
A help document with instructions on how to use the application is provided at the top of the screen to help users navigate their way through the application. Communes in which TBF has installed at least one bio-sand water filter are shown in color, while communes without TBF water filters are shown in gray. The communes are labeled to allow the user to choose a commune of interest. There are four radio buttons that the user can check to focus on one of the four variables (livestock, food storage, sickness, and transportation).

The example shown in the Figure 6-2 illustrates what the user would see if he/she decides to look at the impact TBF has had on a particular commune such as Peak Snaeng. Once the user clicks on Peak Snaeng, an information template appears that contains information relevant to this commune.

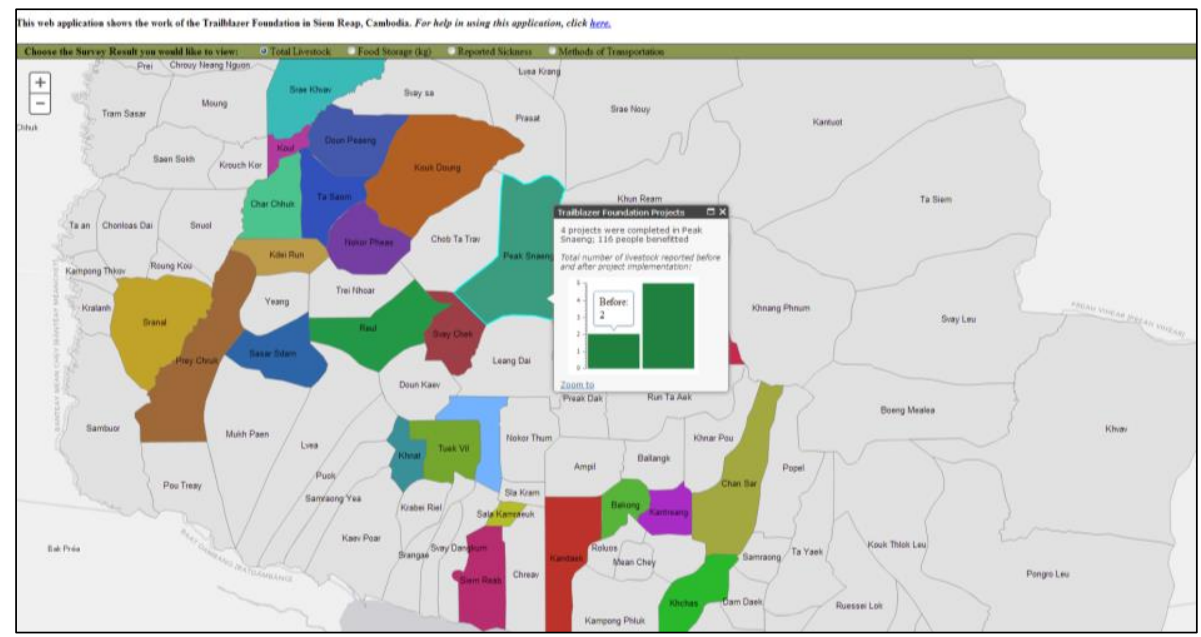

Figure 6-2: Livestock Variable

With the "Total Livestock" radio button selected, the user will see the results of the total number of livestock owned by the beneficiaries in the commune from the baseline and follow up surveys in the form of a bar chart. When the user rolls over the bar chart, the total appears as a pop-up within the info template. In the case of Peak Snaeng, there are 4 projects completed, and 116 people in total benefited from those 4 projects. The number of livestock has increased from 2 to 5 since the projects were implemented in this commune. The information provides the user with some context as to the sample size for impact evaluation. 


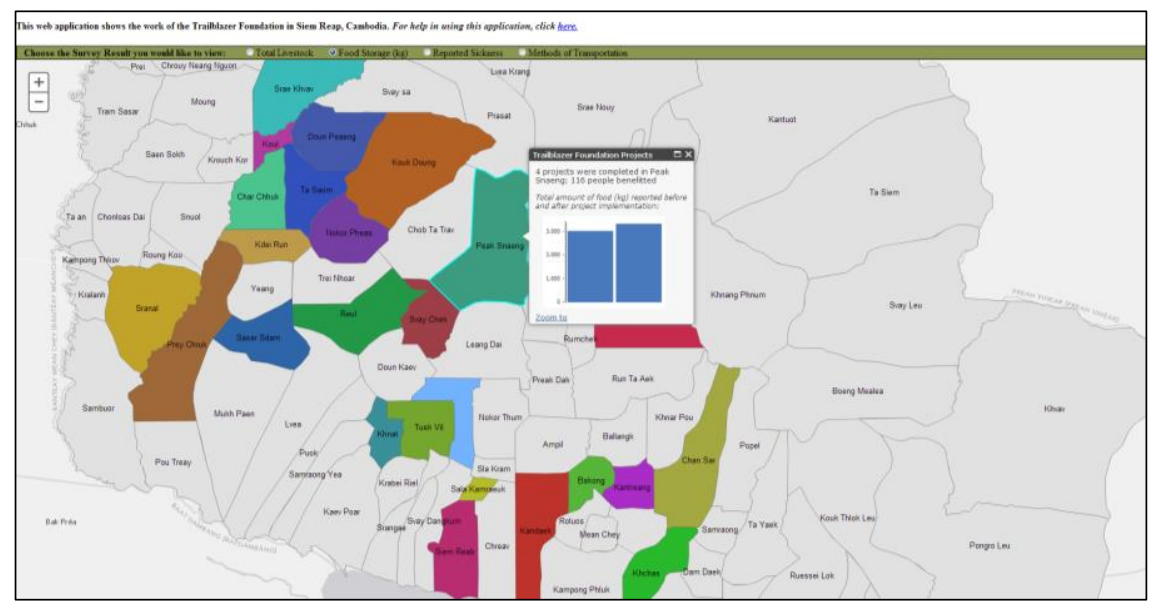

Figure 6-3: Stored Food Variable

Figure 6-3 shows the radio button for "Food Storage" selected and the corresponding info template showing the results of Xfood that is the total amount of food the beneficiaries had in storage from the baseline and follow-up surveys. When the user rolls over the bar chart, the pop-up shows a comparison of the amount of stored food in kilograms $(\mathrm{kg})$ before and after the water filter was installed. In this case, the 116 beneficiaries had roughly $2,000 \mathrm{~kg}$ more stored food at the time of the follow-up survey than they did during the baseline survey, which suggests a positive change related to biosand water filters.

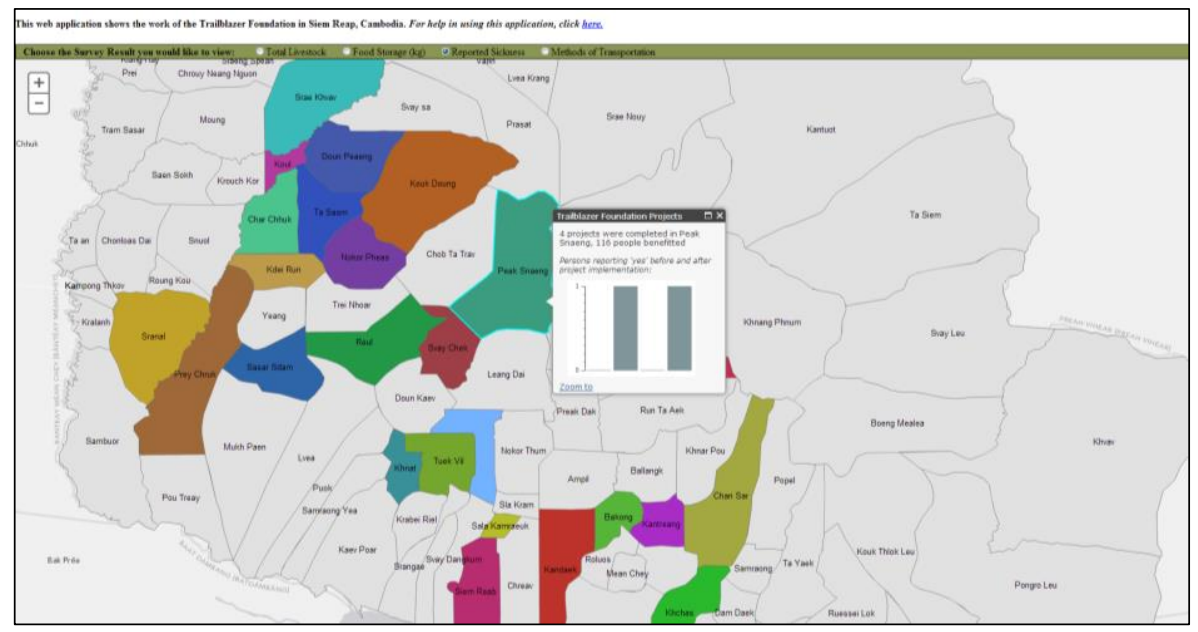

Figure 6-4: Sickness Variable

When the user selects the "Reported Sickness" radio button, the info template presents the total number of projects that involved people who had either diarrhea or other sickness. Although the cases of diarrhea and other sickness are separated in the original survey design, it was decided to combine the two variables into one info template to minimize the number of radio buttons the user must click through. According to Figure 6-4, none of the four projects in Peak Snaeng had reported diarrhea and sickness at the time of baseline survey was conducted; however, the beneficiaries of one project reported 
diarrhea and/or sickness after the project was implemented, keeping in mind these data do not reflect the actual impact of the projects as it was synthetically generated..

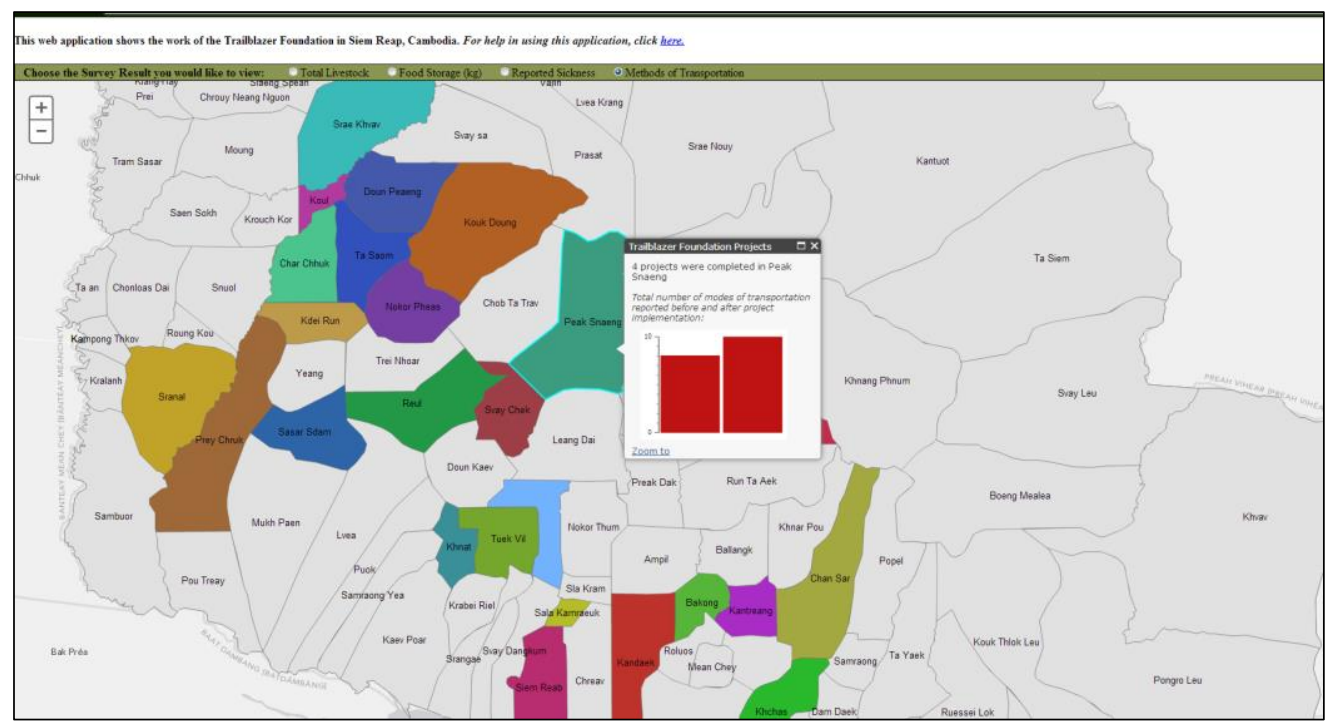

Figure 6-5: Transportation Variable

The final option, "Methods of Transportation" shows the number of transportation vehicles available to the beneficiaries at the time when the baseline and follow-up survey were conducted, as shown in Figure 6-5. This option allows the user to identify how the availability of transportation to the beneficiaries has changed over time. In this case, the number of transportation vehicles has increased in Peak Snaeng from 8 to 10 since the projects have been implemented.

Once the user has viewed the results from all variables, he/she would gain a better understanding of the conditions in that commune and the impact TBF has had on the lives of the beneficiaries. Although the survey results comparison cannot conclusively tell that TBF projects was the only cause for the changes, it gives the potential donor confidence that TBF is keeping track of local conditions and the potential impact of funded projects. Hopefully, this confidence in TBF's work will encourage future donations to its foundation.

\subsubsection{Web Application for Trailblazer Foundation Staff and Board Members}

The second use case deals with a TBF staff member accessing the internal use application to query the database for projects that meet specific criteria to aid in the completion of reports and marketing pieces. Two kinds of queries were implemented: query by donor name or by year. In the case of searching for a specific donor, the user can share information with that donor organization, providing a personalized report of how and where their donations are being spent by TBF. 


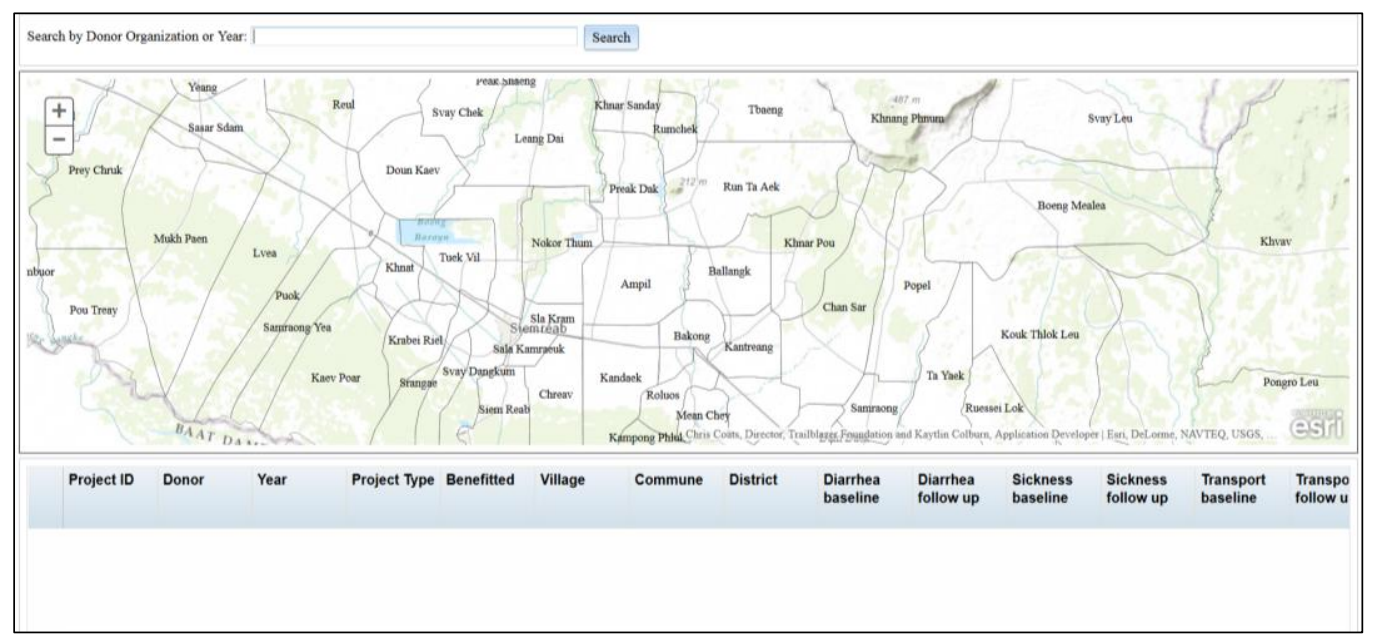

Figure 6-6: Internal Use Application

Figure 6-6 shows the application before a search criterion has been specified. The map is centered on Siem Reap and the communes are labeled to give more geographic context. In the following example, the user is interested in locating all projects funded by anonymous donors. After the user type "anonymous" into the search box, the search results will be returned as shown in Figure 6-7.

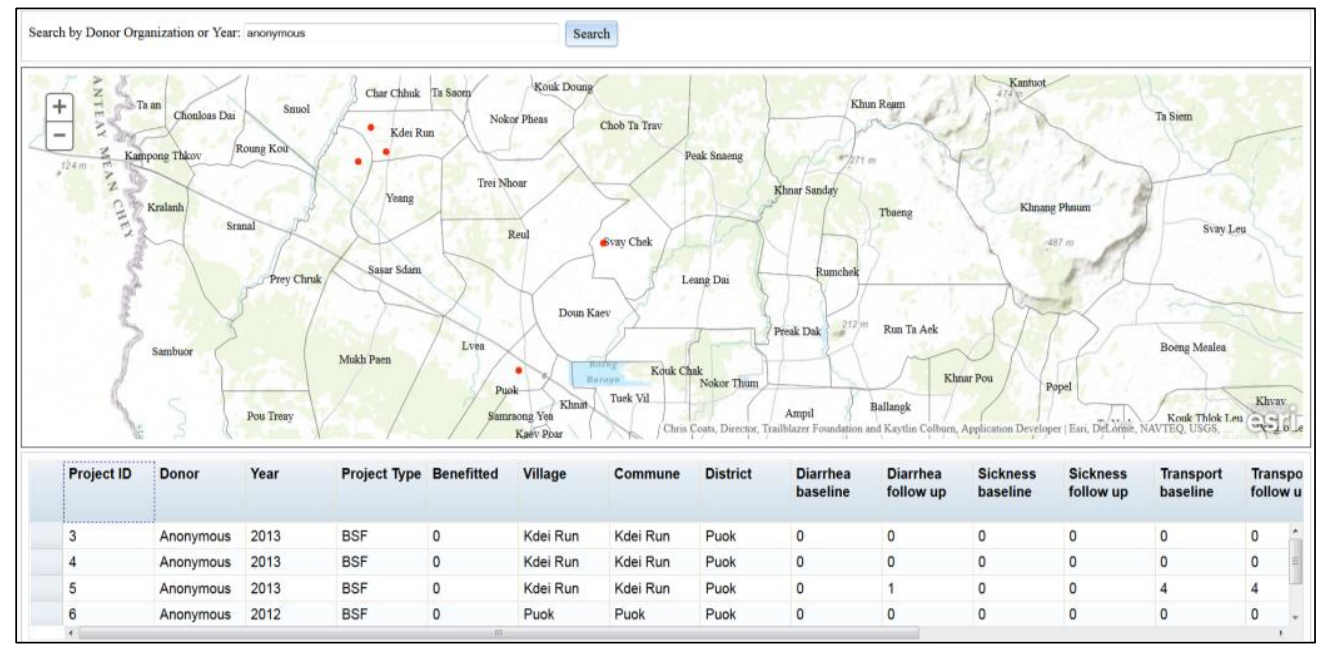

Figure 6-7: Internal Application - Search for Anonymous Donors

The user finds that six projects have been funded by anonymous donors, and how those projects are related to each other spatially in Siem Reap. When the data table populates, the user can click on an entry and the map will zoom to the corresponding project point on the map. From there, the user can further explore the differences and similarities between the projects funded by an anonymous donor and report their findings to board members and other TBF staff members.

Compared to Microsoft Excel spreadsheets, geographic context and spatial distribution of the projects can be viewed on the map with sematic information provided in the table, which offers a more intuitive and streamlined way to query the projects 
funded by a particular donor or in a specific year. The interface facilitates the TBF staff to compare local differences within that category of projects on the map. Meanwhile, the identity of donor organizations and beneficiary locations are protected by limiting the access to TBF staff members.

\subsection{Analyses of Impacts}

In addition to presenting the projects to both public users and the staff and board members, statistical analyses were conducted to examine the impact of the TBF projects on the local communities. First, according to the surveys collected in 2012, 268 bio-sand water filters were installed in Siem Reap by TBF and a total number of 2,545 beneficiaries were involved in the 2012 projects, which is about $0.2 \%$ of the population of Siem Reap. From January to July 2013, 240 bio-sand water filters were installed and a total number of 5,948 beneficiaries were involved in the 2013 projects, which is about $0.6 \%$ of the population of Siem Reap. The analysis involved a total of 508 bio-sand water filters, 8,493 total beneficiaries, which is about $0.9 \%$ of the population of Siem Reap (National Institute of Statistics, 2008). Figure 6-8 is a map of Siem Reap that shows the distribution of projects completed by TBF as compared to the population density of the commune in which the project was completed. It seems most of funded projects were located in the areas with high population; however some of the most populated areas in the southeast of the province have not received enough donations.

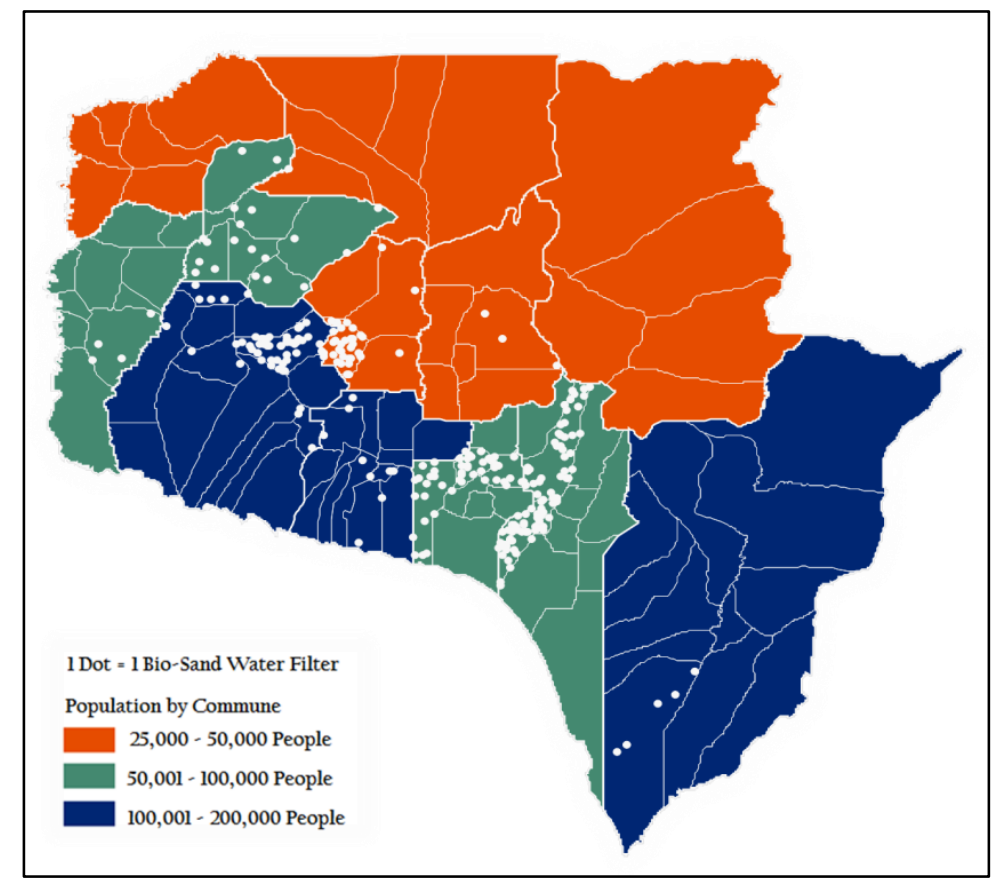

Figure 6-8: Dot-Density Map of Bio-Sand Water Filters

The statistical analyses performed on the survey data were a comparison of the baseline and follow-up survey results. The goal of the analyses was to determine if there was a significant increase in the number of livestock, modes of transportation, and stored food available to the beneficiaries of each project, as well as determine if there was a 
significant decrease in the proportion of the number of projects that had reported sickness The results of these tests would help TBF to determine if its projects have had a positive impact on the lives of the beneficiaries.

A paired t-Test was used to determine if there was a significant change in the average of livestock, transportation, and stored food available to the beneficiaries. Ideally, TBF would want to find a significant positive increase in these variables, because this would indicate a positive impact on the lives of the beneficiaries of the TBF projects.

Table 6-1 summarizes the testing results for 2012 projects, 2013 projects, and all projects.

\section{Table 6-1: Paired t-Test Results}

\begin{tabular}{|c|c|c|c|c|}
\hline Variable & Year & Baseline & Follow Up & Difference (Follow Up - Baseline) \\
\hline $\bar{X}_{\text {transport }}$ & 2012 & 1.42 & 1.94 & $0.52^{*}$ \\
\hline $\bar{T}_{\text {livestock }}$ & 2012 & 6.61 & 7.10 & $0.49^{*}$ \\
\hline$T_{\text {food }}$ & 2012 & 775.35 & 826.94 & $51.59^{\star}$ \\
\hline \multicolumn{5}{|c|}{ Total Projects Completed in 2012: 268} \\
\hline $\bar{T}_{\text {transport }}$ & 2013 & 0.92 & 1.35 & $0.43^{*}$ \\
\hline$T_{\text {livestock }}$ & 2013 & 2.35 & 2.82 & $0.47^{*}$ \\
\hline$T_{\text {food }}$ & 2013 & 769.31 & 817.72 & $48.41^{*}$ \\
\hline \multicolumn{5}{|c|}{ Total Projects Completed in 2013: 240} \\
\hline$\overline{T_{\text {transport }}}$ & All & 1.19 & 1.65 & $0.46^{*}$ \\
\hline$T_{\text {livestock }}$ & All & 4.60 & 5.07 & $0.47^{*}$ \\
\hline$T_{\text {food }}$ & All & 772.50 & 821.25 & $48.75^{*}$ \\
\hline \multicolumn{5}{|c|}{ Total Projects: 508} \\
\hline${ }^{\star}=p<0.01$ & & & & \\
\hline
\end{tabular}

As expected, each variable exhibits a positive and significant change after the projects were implemented $(\mathrm{p}<0.01)$. This is because the follow-up survey data was designed to show an increase in each the variables. This analysis is representative of what TBF could expect if they observe a significant increase in the living conditions in the lives of its beneficiaries.

Next, to determine the significance of the difference in the sickness and diarrhea variables, a difference of proportions z-test was performed. The sickness and diarrhea variables were measured as binary variables, with one indicating there was at least one beneficiary of the project suffering from diarrhea or other sickness, and zero indicating that none of the beneficiaries for that project showed signs of sickness. The proportions of the projects that involved sickness or diarrhea in the baseline and follow-up survey were compared. Similarly, this test was performed on the individual project data in 2012, 2013, and on all projects combined. 
Table 6-2: z-test Results

\begin{tabular}{|c|c|c|c|c|}
\hline Variable & Year & Baseline & Follow-Up & Difference (Follow Up - Baseline) \\
\hline $\bar{T}_{\text {diarrhea }}$ & 2012 & $116(43.2 \%)$ & $67(25 \%)$ & $-49(-18.2 \%)^{*}$ \\
\hline$T_{\text {sickness }}$ & 2012 & 50 (18.6\%) & $7(2.6 \%)$ & $-43(-16 \%)$ \\
\hline \multicolumn{5}{|l|}{ Total: 268} \\
\hline$\overline{T_{\text {diarrhea }}}$ & 2013 & $35(14.5 \%)$ & $50(20.8 \%)$ & $15(6.3 \%)$ \\
\hline $\bar{T}_{\text {sickness }}$ & 2013 & $9(3.7 \%)$ & $13(5.4 \%)$ & $4(1.7 \%)$ \\
\hline \multicolumn{5}{|l|}{ Total: 240} \\
\hline$\overline{\bar{X}_{\text {diarrhea }}}$ & All & $151(29.7 \%)$ & $117(23 \%)$ & $-34(-6.7 \%)^{*}$ \\
\hline$T_{\text {sickness }}$ & All & $59(11.6 \%)$ & $20(3.9 \%)$ & $-39(-7.7 \%)$ \\
\hline \multicolumn{5}{|l|}{ Total: 508} \\
\hline${ }^{*}=p<0.0$ & & & & \\
\hline
\end{tabular}

According to Table 6-2, when all projects are considered, an overall decrease in both variables was observed, with a significant decrease in diarrhea $(\mathrm{p}<0.05)$. This is expected, as the follow-up data was designed to show an overall decrease in these two variables. Projects in 2012 also present an overall decrease in both variables, with a significant decrease in diarrhea $(\mathrm{p}<0.05)$. Projects in 2013, however, show an insignificant increase in both variables. These varied results are representative of what TBF might expect to see if they perform the same test on its follow-up survey data when it becomes available.

It is important to bear in mind that the above analyses only provide the evidence of changes in these variables, not implying any causality. For example, even if TBF finds a significant increase in food storage using its true survey data, it does mean the bio-sand water filters is the only cause for the positive change. To further answer this question, other factors that could influence the lives of beneficiaries should be considered simultaneously in the analysis.

\subsection{Summary}

This chapter discusses the results of the analyses as well as the functionality of the applications through use cases. The use cases considered for this project implementation are discussed from the perspective of the two kinds of users that would use the application - public users such as a potential donor learning about TBF, and an internal user such as a TBF staff member. Ultimately, the public use application allows the users to gain a better understanding of the change in lives of beneficiaries over time. The internal use application provides a platform for TBF staff to interact with its data in a way that leverages the spatial component of its survey data as well as enhances data visualization.

The statistical analyses are also discussed in this chapter. The analyses evaluate the impact of the projects over time by determining which variables exhibits a significant increase or decrease when the baseline survey results re compared to the follow-up survey results. A paired t-Test was performed on the three continuous variables; livestock, transportation, and stored food. A difference of proportion z-test was performed on the two binary variables: diarrhea and other sickness. While these data are not comprehensive enough to conclusively state that the presence of TBF bio-sand water filters was the direct cause for a significant increase or decrease in a certain variable, this 
analysis offers an insight into the impact TBF has had on its beneficiaries. The next chapter will provide a conclusion to this report as well as a reflection on the project and steps that can be taken in the future. 



\section{Chapter 7 - Conclusions and Future Work}

This project set out to change the way the Trailblazer Foundation interacts with its data and communicates with its current and potential donors and board members the impact their donations have in Siem Reap, Cambodia through international aid. This was accomplished first by organizing the data in a way that highlighted the spatial components. Statistical analyses were performed to measure changes in the living conditions of the beneficiaries of TBF's bio-sand water filters. Then, the data were served to the Web in two separate applications meant for different audiences. One for the general public that aggregated the data at the commune level and presented a cursory look at the impact the Trailblazer Foundation has had on Siem Reap as a whole. Another part of the application served the Trailblazer Foundation internally for the purpose of the staff to gain a better understanding of where its donors' money was being spent, and to get a feel for how the area was changing year after year as new surveys were taken of its beneficiaries. Ultimately this project significantly changed the way Trailblazer Foundation staff interacts with its data. While this project is only a proof of concept, it has laid the groundwork for a powerful tool to help TBF increase its donations.

Each of the functional and non-functional requirements outlined in Chapter 3 were ultimately met by the final product. The functional requirements included creating a web application, conduct statistical analysis, and include functionality to search for projects based upon the donor name or year in which the projects were completed. The nonfunctional requirements included an intuitive user interface, the creation of a geodatabase appropriate for the Web, and publishing services to ArcGIS Online. Web applications appropriate for public and for internal use were developed for the client. While it was originally thought to be one application, two applications were developed to meet the requirement of keeping sensitive donor and beneficiary information private. The statistical analysis was presented in the application, aggregated at the commune level. An intuitive interface was designed for each application. To accomplish this, the search function was only included in the application intended for internal use for the Trailblazer Foundation, and the public application only includes the aggregated analysis results, presented in an info template.

During a discussion with Trailblazer Foundation staff, Jeni Swink, it was revealed that the Trailblazer Foundation had in the past taken note of the type of roof villagers had before they installed a bio-sand water filter and after. They found that the type of roof improved tremendously after its project had been implemented for a few years, the reason being the beneficiaries of the TBF project experienced improved health, and were able to therefore bring in more income to the family, allowing them to purchase a more stable roof. TBF found the improvement in roof type was loosely related to an improvement in overall living conditions of the beneficiaries as a result of a project in which TBF was involved. When the data originally planned to be included in the project were not available, census data were used to determine a change or improvement of living conditions for beneficiaries of TBF water filters. This information would be compared with areas not served by the client, and the results would be displayed in the web application originally agreed upon. However, the data were not conclusive enough to say 
that any changes in the census data were a direct result of the presence or absence of TBF projects because the scale was too coarse.

A great deal of effort then went into locating a dataset that contained the kind of information needed for the project. After much searching through the available resources, the Commune Database Online (CDBO) was found to be the most useful, for it contained information about housing status and roof types within the communes of Siem Reap. Once the data were located, the task of converting the data from CDBO into a format that could be consumed by ArcGIS began. Data from ArcGIS Online were used for the boundaries of the districts and communes within Cambodia, though only data pertaining to Siem Reap were clipped out for use in this project. These data have been collected by the Global Agriculture and Food Security Program (GAFSP). Attributes from CDBO were joined with the boundaries from GAFSP to create the feature classes that would then be used in the feature services published for the web application. Unfortunately, census data of Cambodia were only available at the district and commune level, which was not suitable for the analysis of changes that occurred at the neighborhood level. To overcome this problem, an analysis framework was set up with simulated follow-up survey data. When the follow-up surveys are conducted in the future, the client can use this framework to analyze the before and after change directly.

The applications are not without their limitations. The biggest limitation is the use of synthetic data in the absence of real follow-up data. TBF will not be able to use the application in any real sense until the follow up survey data for the projects included in the application have been collected. This project serves only as a proof of concept for demonstration purposes until this data is collected and replaces the synthetic data.

Looking ahead into the future of this project, there are several steps that can be taken to enhance the finished product. First and foremost, when TBF collects follow-up data on the projects implemented in 2012 and 2013, that data will replace the synthetic data used for the purposes of this project. When that happens, the application will be ready to be served out to the general public and used for its intended purposes. Additionally, TBF may consider adding historical project data to give a broader picture of the impact they have had on communities over the years. With the addition of historical data, further analysis could be included in the application, as well as time animation in the form of a time-slider. Another next step for this project would be the development of a mobile application for field staff to enter survey data into directly. This could be especially useful for the internal application, allowing staff at the headquarters office to see the data in real-time.

Though the surveys conducted by TBF are not comprehensive enough to gain a full picture of the water crisis in Siem Reap, web GIS can help to complete the picture by revealing spatial relationships through visualization and analysis. In addition, by making this information available to a wider audience and thus increasing awareness of the situation many who live in Siem Reap may find themselves, society as a whole becomes closer to its moral obligation to ensure all people have the chance to live a healthy and productive life which hinges on having access to enough clean water. 


\section{Works Cited}

Adnan, M., Singleton, A., \& Longley, P. (2010). Developing Efficient Web-based GIS Applications. CASA Working Papers Series, 153, Centre for Advanced Spatial Analysis (UCL): London, UK, 1-15.

Dragicevic, S., \& Balram, S. (2004). A Web GIS Collaborative Framework to Structure and Manage Distributed Planning Processes. Journal of Geographical Systems, 133-153.

Fike, R. (2007). How GIS is changing Loma Linda Univeristy Medical Center's view of the world. Retrieved December 2013, from ArcNews Online: http://www.esri.com/news/arcnews/fall07articles/loma-linda.html

Fu, P., \& Sun, J. (2011). Web GIS Principles and Applications. Redlands: Esri.

Gleick, H. (1998). Water in Crisis: Paths to Sustainable Water Use. Ecological Applications, 8(3), 571-579.

Haklay, M. (2010). Interacting with Geospatial Technologies. Chichester, West Sussex: John Wiley \& Sons Ltd.

Hansen, H., \& Tarp, F. (2000). Policy Arena Aid Effectiveness Disputed. Journal of International Development, 375-398.

Jankowski, P., Tsou, M.-H., \& Wright, R. (2007). Applying Internet Geographic Information System for Water Quality Monitoring. Geography Compass, 1/6, $1315-1337$.

Kraak, M.-J. (2004). The role of the map in a Web-GIS environment. Journal of Geographical Systems, 83-93.

Li, S., Xiong, C., \& Ou, Z. (2011). A Web GIS for Sea Ice Information and an Ice Service Archive. Transactions in GIS, 15(2), 189-211.

Mathiyalagan, V., Grunwald, S., Reddy, K., \& Bloom, S. (2005). A WebGIS and geodatabase for Florida's wetlands. Computers and Electronics in Agriculture, 6975.

Ministry of Planning, National Institute of Statistics (2008). General Population Census of Cambodia 2008. Phnom Penh, Cambodia: National Institute of Statistics, Ministry of Planning.

Overton, J., Murray, W. E., \& McGregor, A. (2013). Geographies of Aid: A Critical Research Agenda. Geography Compass, 116-127.

Peng, Z.-R. (1999). An Assessment Framework of the Development Strategies of Internet GIS. Environment and Planning B: Planning and Design, 117-132.

Peng, Z.-R., \& Zhang, C. (2004). The roles of geography markup language (GML), scalable vector graphics (SVG), and Web feature service (WFS) specifications in the development of Internet geographic information systems (GIS). Journal of Geographical Systems, 6, 95-116.

Romalewski, S. (2004). CMAP's GIS Service Bureau Strengthens New York's Nonprofits. Retrieved from ArcNews Online: http://www.esri.com/news/arcnews/winter0405articles/cmaps.html

UNICEF. (2011). UNICEF Cambodia. Retrieved 2013, from Statistics: http://www.unicef.org/infobycountry/cambodia_statistics.html\#105

van Dyke, J. (2010). Working with Esri APIs. Esri California, Hawaii, \& Nevada Regional User Group Conference (pp. 1-12). Redlands: Esri. 
Wilton, P. (2004). Beginning JavaScript, Second Edition. Indianapolis, Indiana: Wiley Publishing.

Zeiler, M. (2010). Modeling Our World. Redlands: Esri. 


\section{Appendix A. Application Code - Internal Use Application}

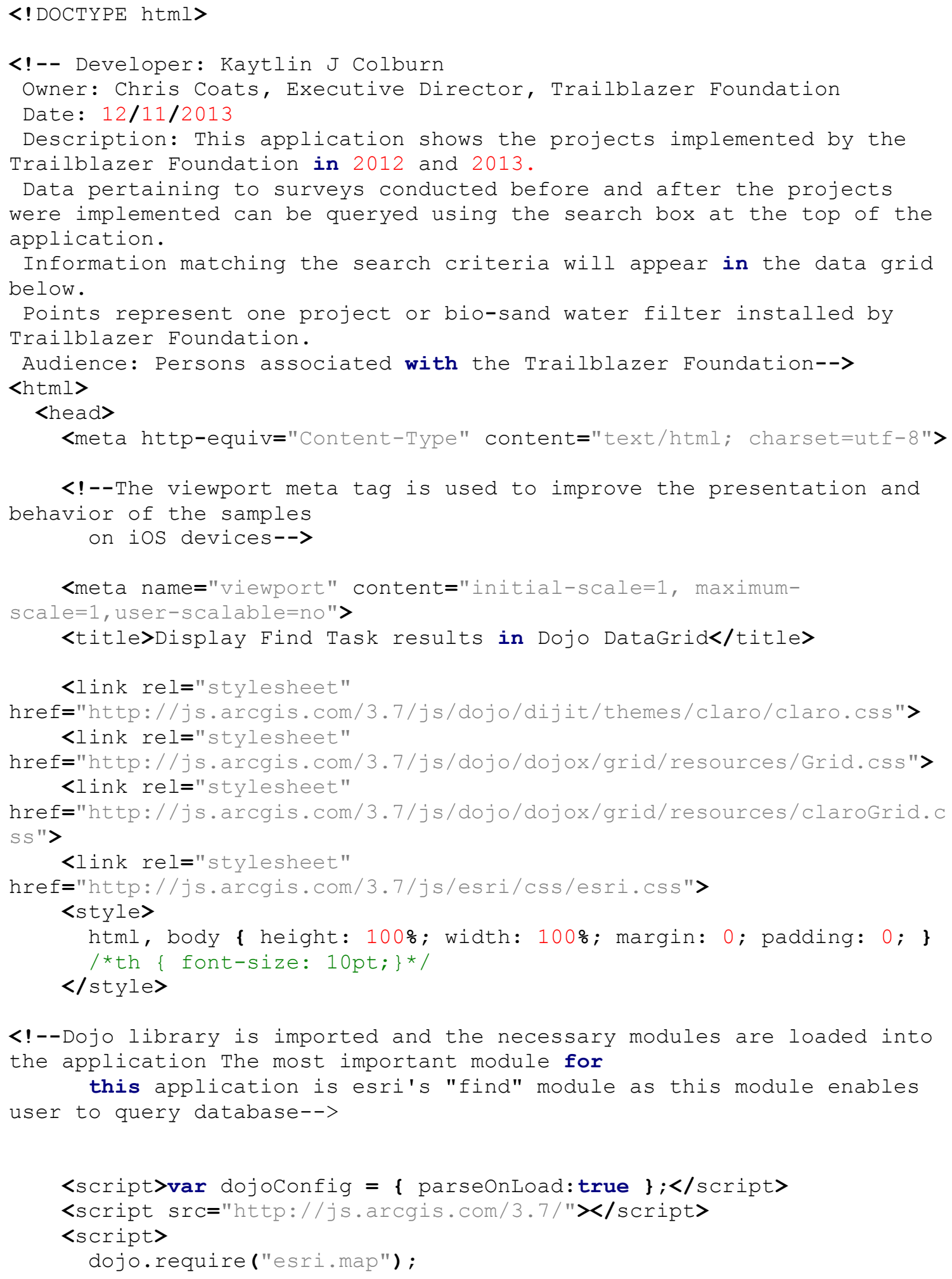




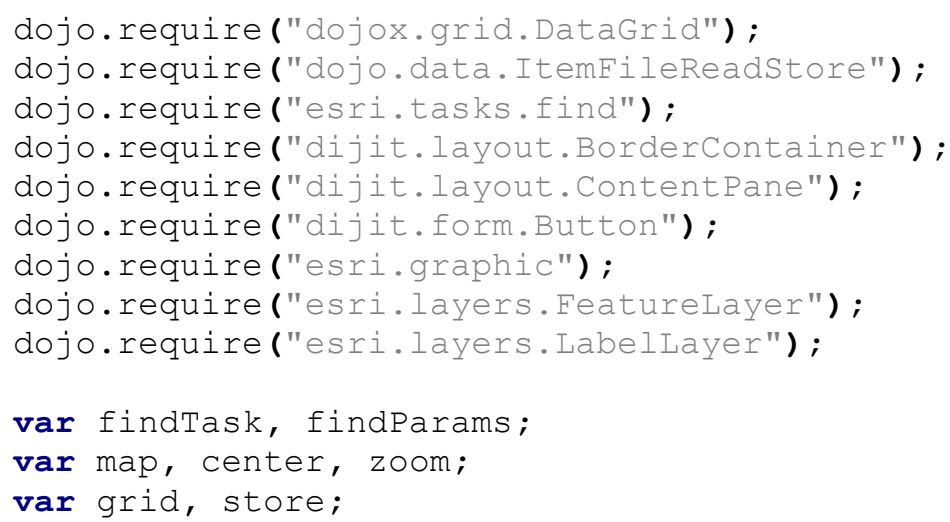

// Center and zoom the map to the appropriate coordinates upon opening the application

// The map will automatically direct the user to Siem Reap, Cambodia at a zoom level of 11

function init() \{

dojo.connect (grid, "onRowClick", onRowClickHandler);

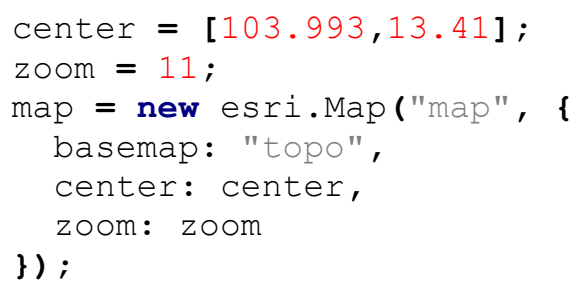




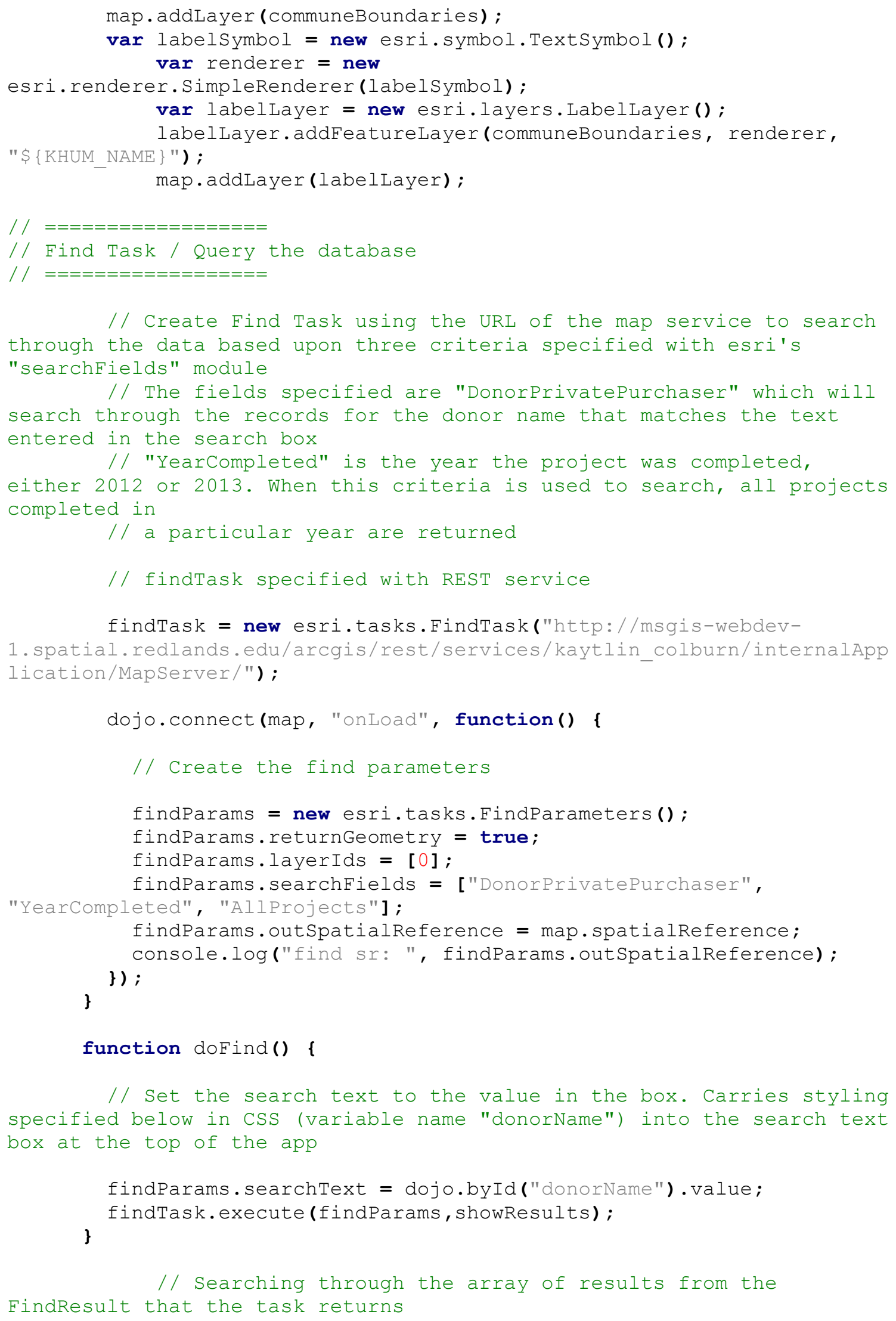


function showResults(results) $\mathfrak{l}$

map.graphics.clear();

var symbol = new

esri.symbol.SimpleMarkerSymbol (esri.symbol.SimpleMarkerSymbol.STYLE_CIR CLE, 6, new

esri.symbol.SimpleLineSymbol (esri.symbol. SimpleLineSymbol.STYLE_SOLID, new dojo.Color $([245,47,7]), 2)$, new $\operatorname{doj} \circ \operatorname{Color}([245,47,7]))$;

// create array of attributes

$\operatorname{var}$ items $=$ dojo.map (results, function(result) \{

var graphic = result.feature;

graphic.setSymbol (symbol);

map.graphics.add (graphic);

return result. feature.attributes;

\}) ;

// Create data object to be used in store. OBJECTID used

because it is unique to each project; This differentiates the projects from each other

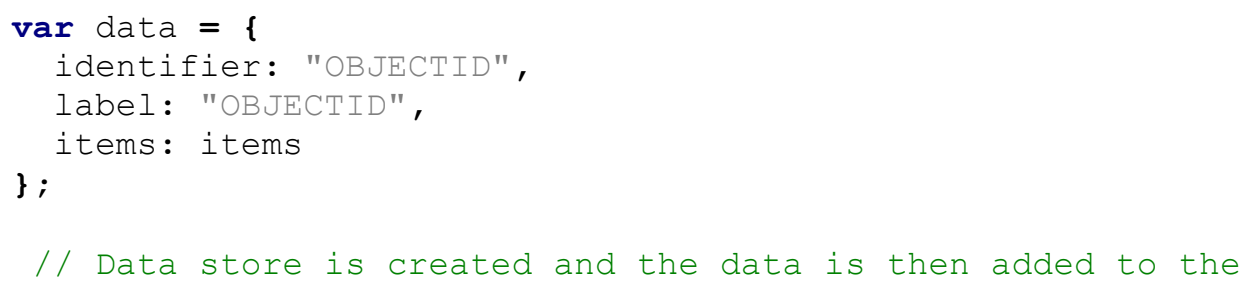


// Check geometry type and zoom accordingly. Geometry type is point and map will zoom to level 13 when record is clicked on

// This switch statement triggers the application to center and zoom to the point of the record that was clicked on by the user

switch (selectedProject.geometry.type)

\{

case "point":

$\operatorname{var} \mathrm{x}=$ selectedProject.geometry.x;

var $y=$ selectedProject.geometry.y;

var mapPoint = new esri.geometry. Point $(x, y$, new

esri.SpatialReference ( \{ wkid: 102100 \}));

map. centerAndZoom (mappoint, 13);

//map. centerAndZoom ( [x, y $], 1.0)$;

// map.centerAndzoom ( [selectedProject.geometry.x, selectedProject.geometry.y], 1.0);

\section{break;}

case "extent":

var extent $=$ selectedProject.geometry.getExtent (); map.setExtent (extent);

\section{break;}

// map.setExtent (selectedProject.geometry.getExtent ()) ;

default:

alert("WARNING: Unexpected geometry type encountered: " + selectedProject.geometry.type);

break;

\}

\section{\}}

dojo.ready(init);

$\langle/$ script $>$

\section{$</$ head $>$}

<body class="claro">

<div data-dojo-type="dijit.layout.Bordercontainer" data-dojoprops="design: "headline'" style="width:100\%;height:100\%;margin:0;">

<div data-dojo-type="dijit.layout. ContentPane" data-dojo-

props="region: 'top'" style="height:40px;">

Search by Donor Organization or Year: <input type="text" id="donorName" size="60" value="2012" />

<button data-dojo-type="dijit.form.Button" data-dojo-

props='onclick:function() \{ doFind(); \}, value:"Search"'>

Search

$</$ button $>$

$\langle/$ div $\rangle$

<div id="map" data-dojo-props="region: 'center'" data-dojotype="dijit.layout.ContentPane" style="border:1px solid \#000;">/div>

<div data-dojo-type="dijit.layout.ContentPane" data-dojoprops="region: 'bottom'" style="height:200px;">

<table data-dojo-type="dojox.grid.DataGrid" data-dojo-id="grid" id="grid" data-dojo-props="rowsPerPage: '18', rowSelector: '40px'">

$<$ thead> 


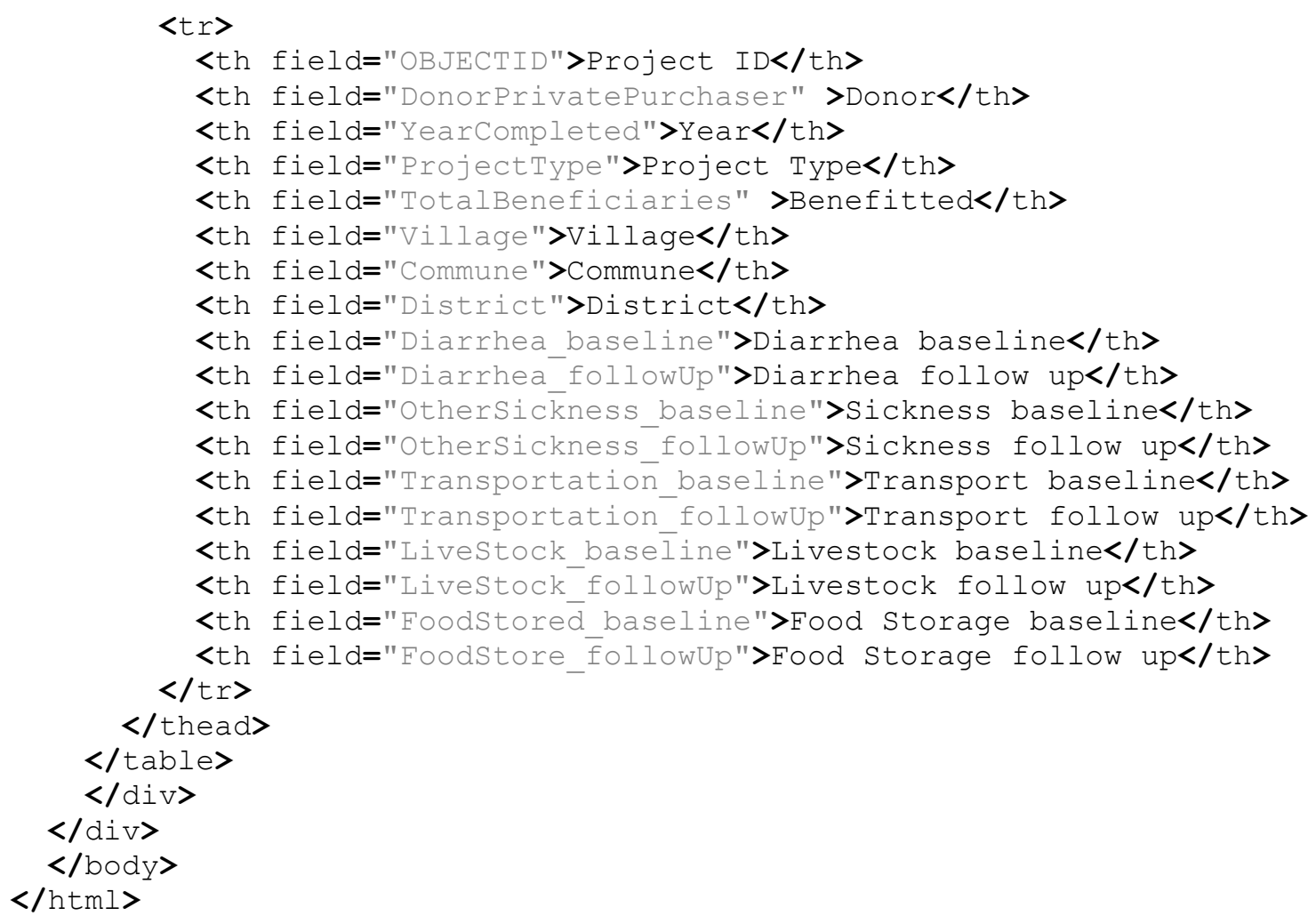




\section{Appendix B. Application Code - Public Use Application}

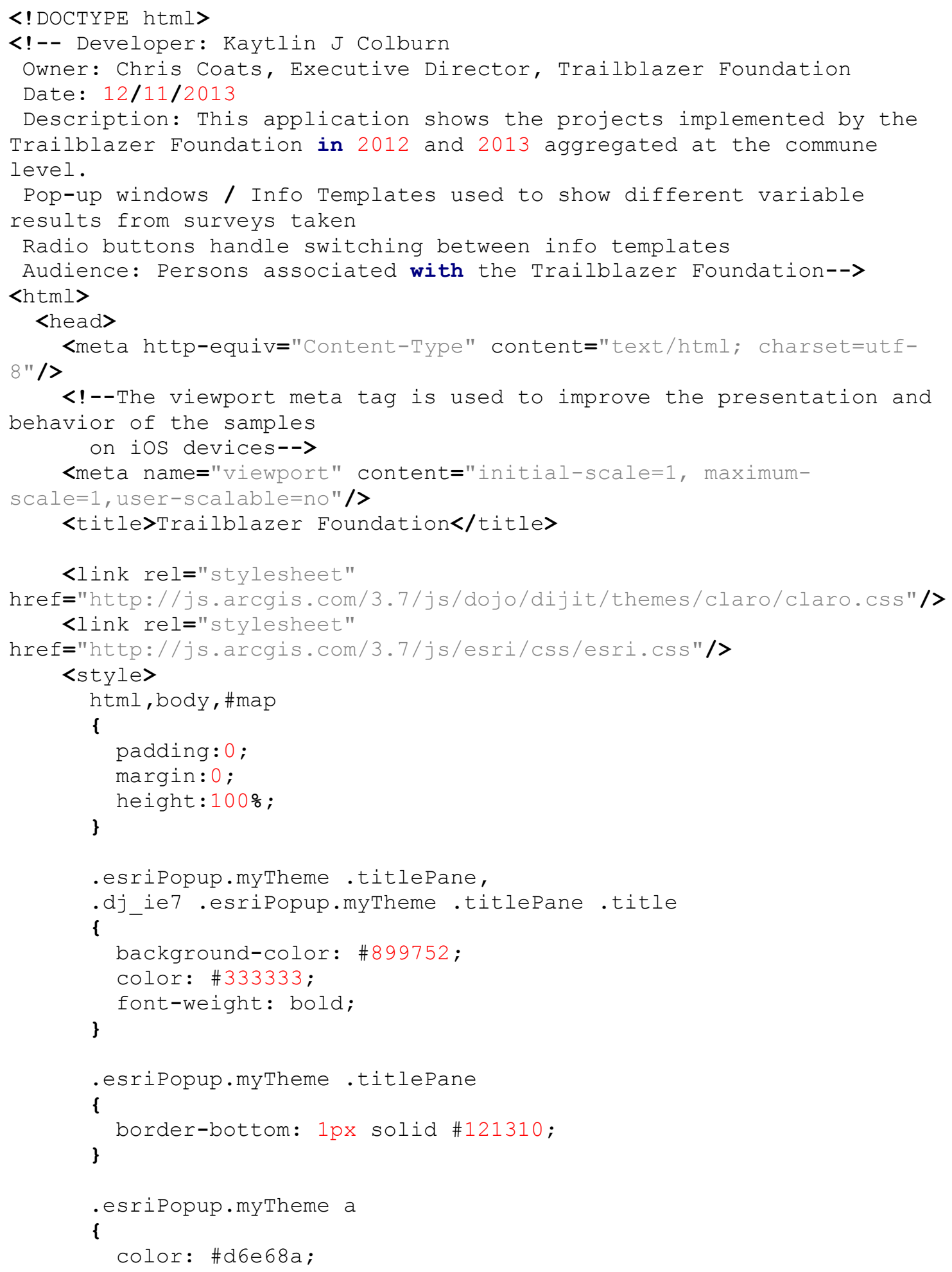




\section{\}}

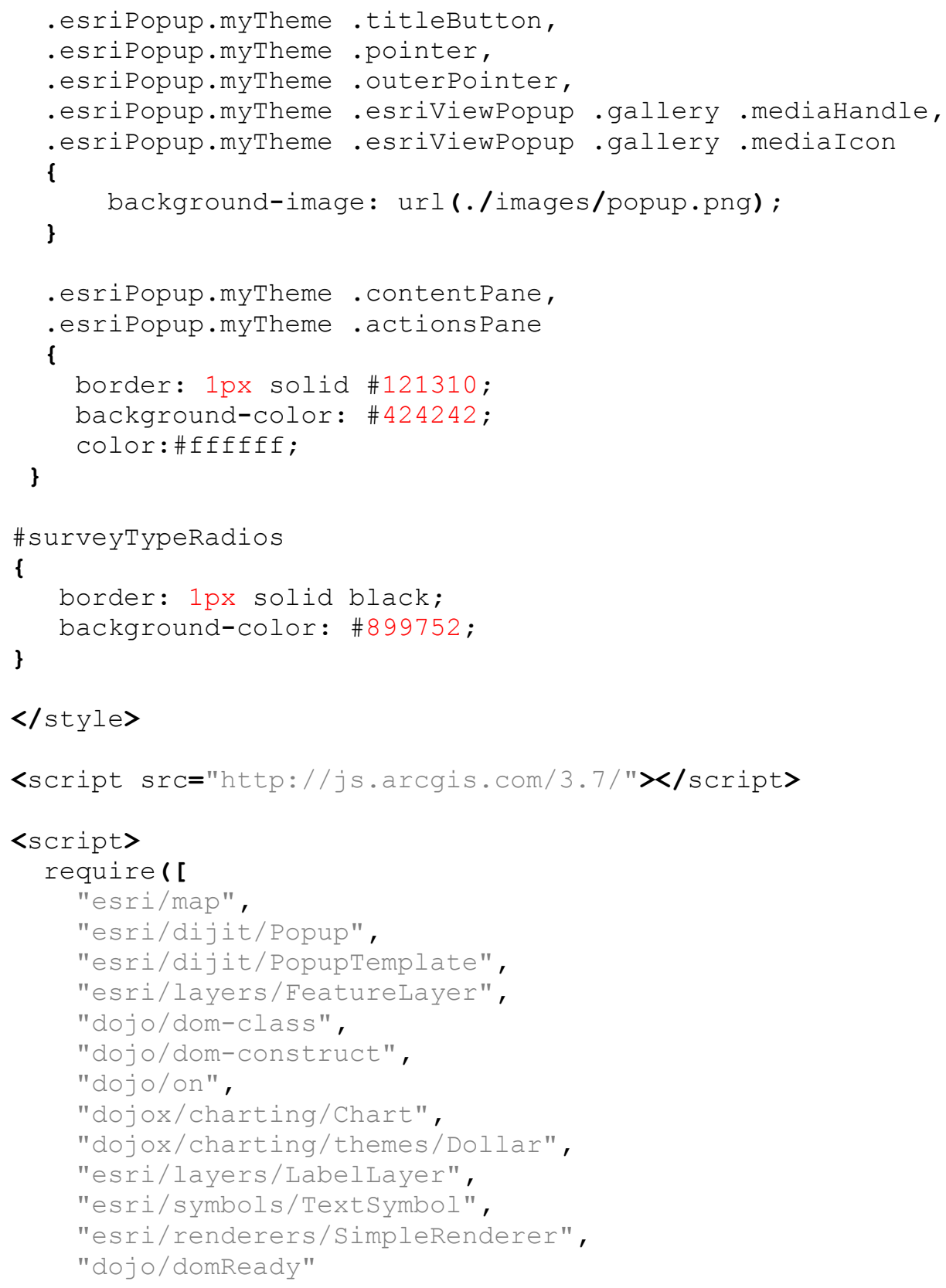

\section{], function(}

Map,

Popup, PopupTemplate, 


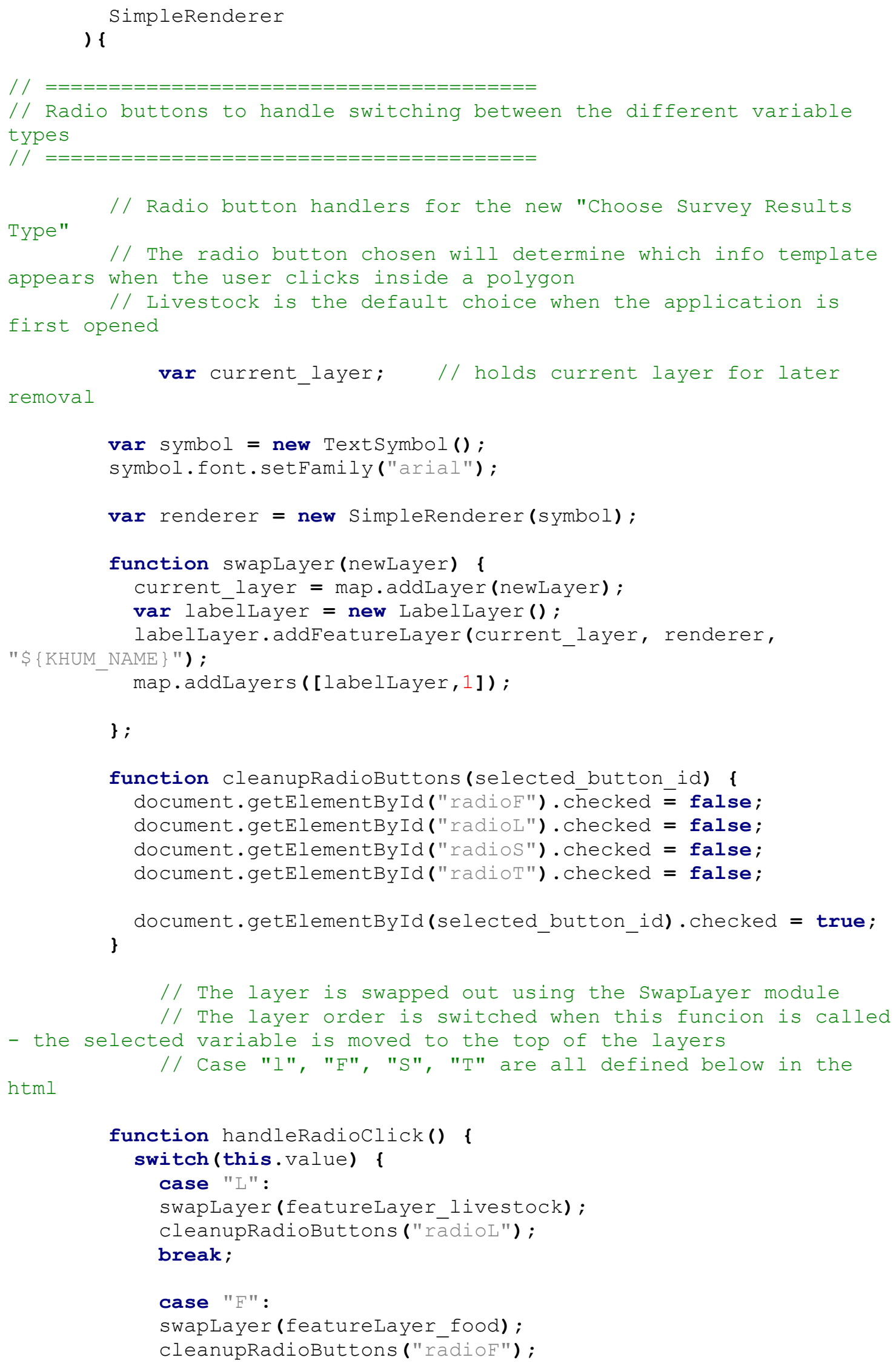




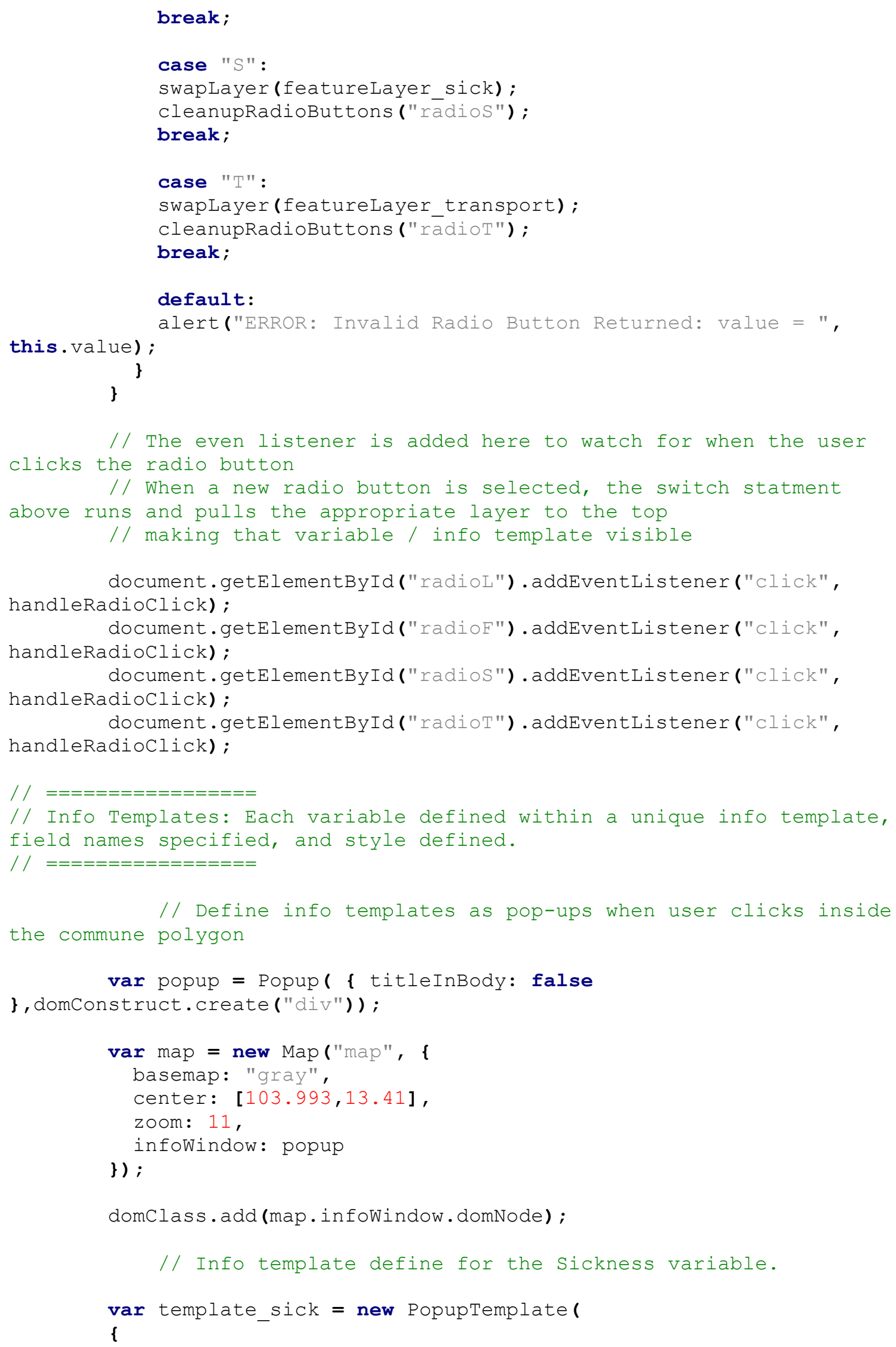


title: "Trailblazer Foundation Projects",

description: "\{Count_\} projects were completed in

$\{$ KHUM_NAME\}, \{Sum_TotalBeneficiaries\} people benefitted", fieldInfos:

[

\{

fieldName: "diarrheaBaselineFloat",

label: "Diarrhea before"

\},

\{

fieldName: "diarrheaFollowUpFloat",

label: "Diarrhea after"

\} ,

\{

fieldName: "otherSicknessBaselineFloat", label: "Other Sickness before"

\},

\{

fieldName: "otherSicknessFollowUpFloat",

label: "Other Sickness after"

\}

],

mediaInfos: [ \{

caption: "Persons reporting 'yes' before and after project

implementation:",

type: "columnchart",

value: \{

theme: "MiamiNice",

fields: ["diarrheaBaselineFloat","diarrheaFollowUpFloat", "otherSicknessB aselineFloat","otherSicknessFollowUpFloat"]

\}

\section{\}]}

\}) ;

// Info template define for the Food stored variable.

var template_food $=$ new PopupTemplate $(\mathfrak{\{}$

title: "Träilblazer Foundation Projects", description: "\{count_\} projects were completed in

\{KHUM_NAME\}; \{Sum_TotalBeneficiaries\} people benefitted", fieldInfos:

[

l

fieldName: "foodBasefloat",

label: "kg Before"

\},

\{

fieldName: "foodFollowFloat",

\}

label: "kg After"

],

mediaInfos: [ \{

caption: "Total amount of food ( $\mathrm{kg}$ ) reported before and

after project implementation:",

type: "columnchart", 


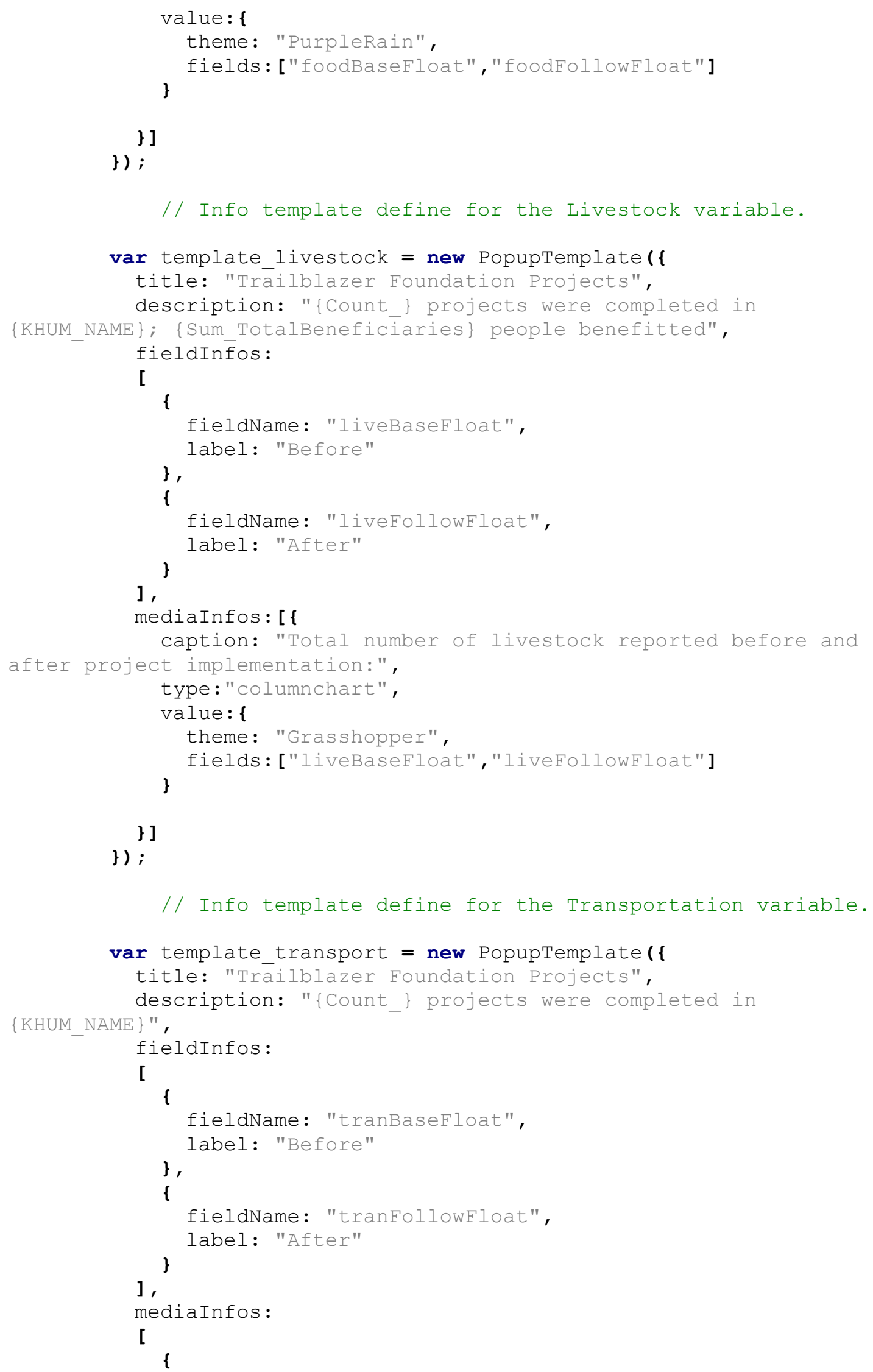


caption: "Total number of modes of transportation

reported before and after project implementation:",

type: "columnchart",

value:

\{

theme: "Shrooms",

\}

fields: ["tranBaseFloat","tranFollowFloat"]

\}

\section{]}

\});

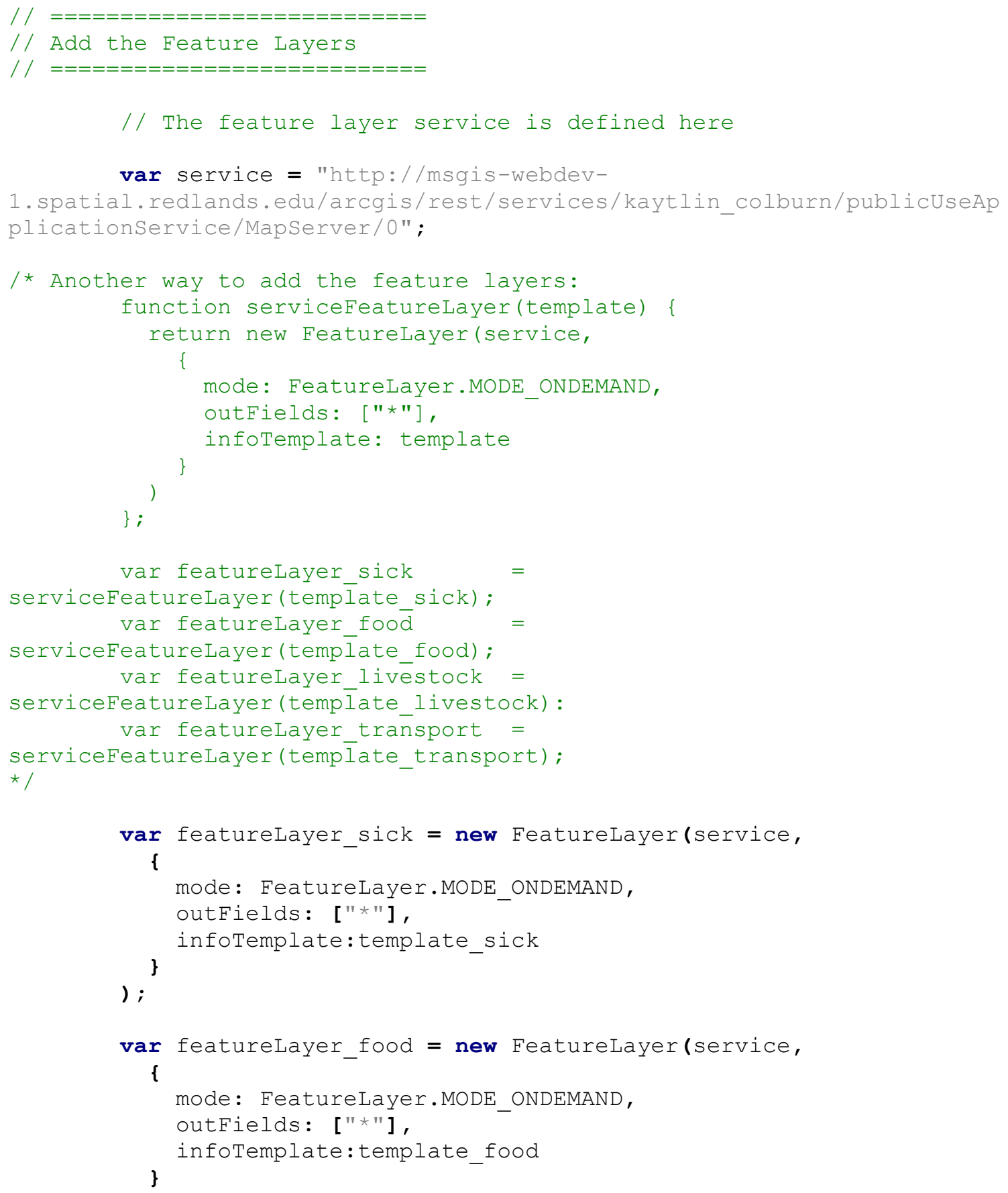




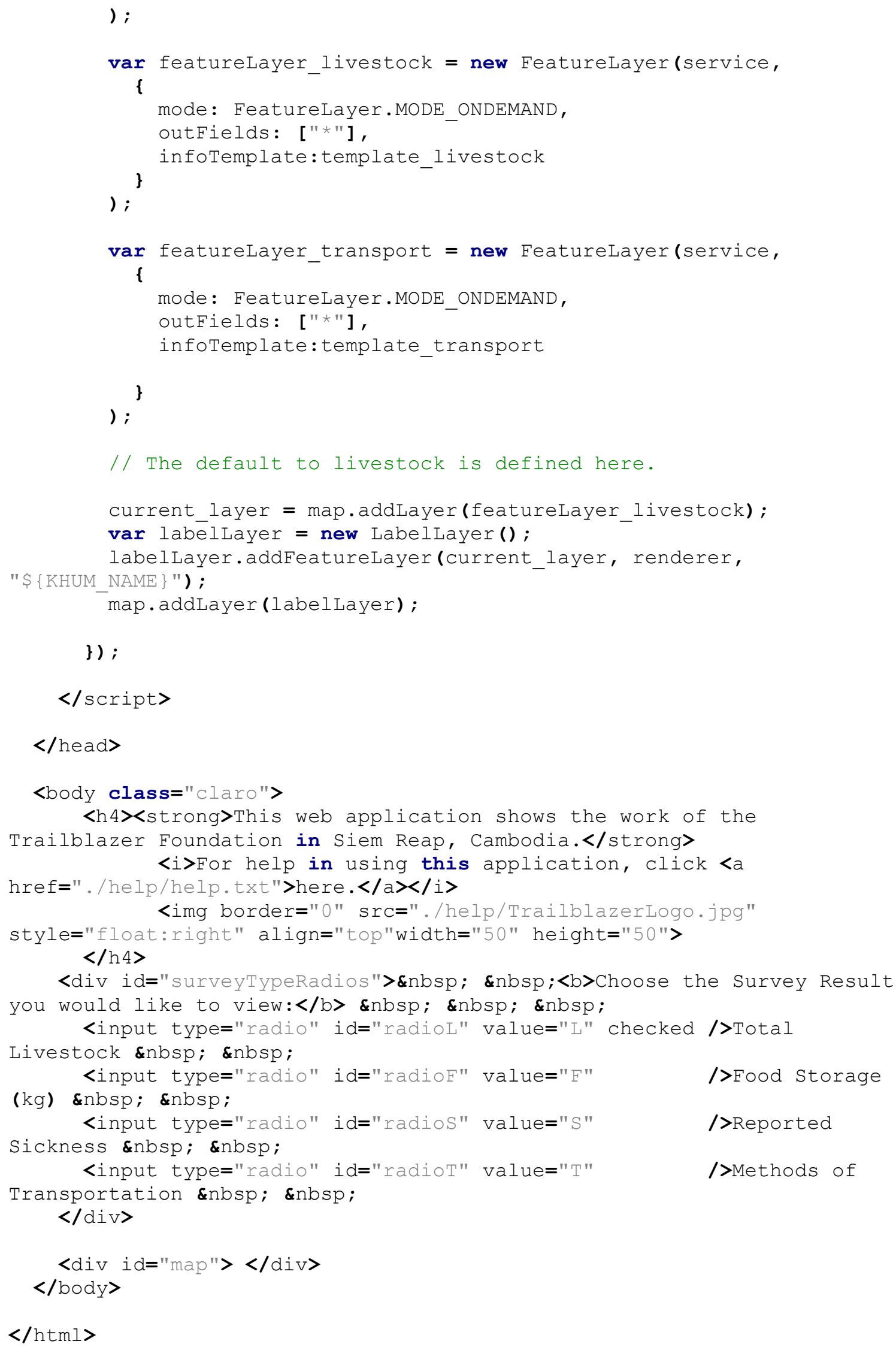




\section{Appendix C. Help Documentation}

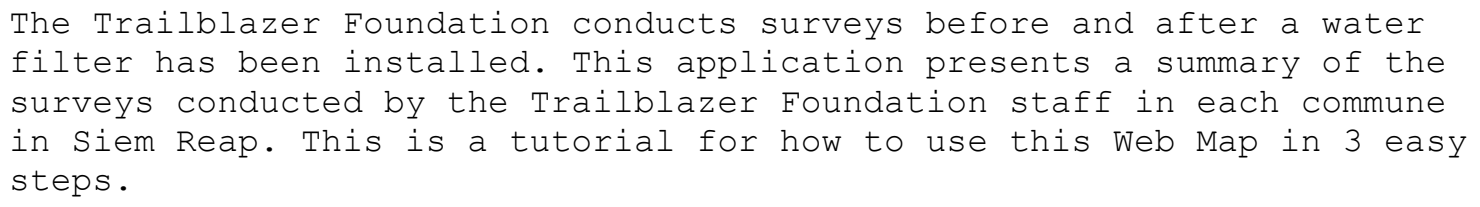

